\title{
La pena de muerte en la reflexión de la Teología Moral y en el Magisterio de la Iglesia
}

\author{
The Death Penalty in the Consideration of Moral \\ Theology and in the Magisterium of the Church
}

\author{
José Manuel Martínez Guisasola \\ Facultad de Teología San Isidoro de Sevilla. Sevilla, España \\ josemanuelmartinez@sanisidoro.net \\ (iD) https://orcid.org/0000-0003-1976-4740
}

\begin{abstract}
Resumen: El presente artículo pretende ser un recorrido diacrónico que ponga de manifiesto las distintas consideraciones y valoraciones morales que la Iglesia, a través del Magisterio, ha realizado con respecto a la cuestión de la pena de muerte, teniendo en cuenta para ello tanto los fundamentos históricos como los teológicos que han servido de basamento en la reflexión de la ética cristiana.
\end{abstract}

Palabras clave: Pena de muerte, Catecismo, Magisterio, ética cristiana.

\begin{abstract}
This article aims to be a diachronic journey that highlights the different moral considerations and evaluations that the Church, through its Magisterium, has carried out with respect to the question of the death penalty. It takes into account both the historical and theological foundations that have served as the basis of the Christian ethics.
\end{abstract}

Keywords: Death penalty, Catechism, Magisterium, Christian ethics

\section{INTRODUCCIÓN}

La pena de muerte es considerada como el castigo más severo que se le puede infligir a un ser humano en tanto que implica la supresión de una vida. A lo largo de la historia muchas y variadas han sido las posturas que se han adoptado ante ella. La Iglesia, que acumula dos mil años de antigüedad, ha reflexionado también sobre esta cuestión. ¿Ha mantenido una postura uniforme en estos veinte siglos? Debemos responder negativamente a la pregunta planteada. La tradición cristiana y el Magisterio eclesiástico han ido dando bandazos con relación a la valoración moral de la pena capital pasando de un 
rechazo absoluto a su aplicación en los primeros siglos del cristianismo a una cierta tolerancia conforme se iba generando la cristiandad europea, tolerancia que dio paso, con el transcurrir del tiempo, a una aceptación de la misma a partir de la escolástica con la imposición de las tesis tomistas. Esta última postura consiguió echar profundas raíces en la moral católica hasta el punto de que llegó a considerársela como sentencia común en teología. ${ }^{1}$ La autoridad intelectual del Aquinate no se cuestionaba sobre esta materia, sino que se intentaba argumentar para justificar lo que el Doctor Angélico ya había sentenciado acerca de la eticidad con respecto a la aplicación de la pena capital al injusto agresor. Esto ha explicado el porqué, durante tantos años, la postura de la Iglesia se había mantenido firme en esta cuestión. Casi era una verdad de fe revelada que había que custodiar. Así se entendió y así lo han entendido quienes se esforzaron por hacer todo lo posible para que la posición oficial del Magisterio no se desviara de esta consideración. En este sentido, hay que reconocer que, en los últimos siete siglos, la Iglesia enseñaba oficialmente y sin ambages que sentenciar a muerte a un ser humano culpable de ciertos delitos gravísimos era algo perfectamente lícito si no había ninguna duda sobre la comprobación de la identidad del malhechor y de su responsabilidad en el delito perpetrado. ${ }^{2}$ Sin embargo, el pontificado del papa Francisco está siendo rompedor en muchas cuestiones en las que parecía que no se podía decir más de lo que ya se había dicho. Entre esas cuestiones está la pena de muerte. De hecho, el papa argentino pasará a la historia, entre otras razones, por haber modificado la posición de la Iglesia con respecto a la valoración moral de la aplicación de la pena de muerte. Si esta, como hemos indicado, gozaba del aval magisterial, desde el año 2018 dicho aval ha sido retirado. Efectivamente, después de un tiempo estudiando la temática, el actual obispo de Roma autorizó la modificación del número 2267 del Catecismo para enseñar, a partir de la fecha indicada, que

1 Cf. Aurelio Fernández, Teología Moral II. Moral de la persona y de la familia, Burgos, Facultad de Teología del Norte de España, 2001³ 801.

2 Estas dos condiciones eran las requeridas por la Iglesia para avalar la licitud de la aplicación de la pena capital. “La enseñanza tradicional de la Iglesia no excluye, supuesta la plena comprobación de la identidad y de la responsabilidad del culpable, el recurso a la pena de muerte, si esta fuera el único camino posible para defender eficazmente del agresor injusto las vidas humanas": CATECISMO DE LA IGLESIA CATÓlicA, n 2267, Madrid, Asociación de Editores del Catecismo, 1999, 605. 
la aplicación de la pena capital es inadmisible por el hecho de que constituye un atentado contra la inviolabilidad de la vida humana. Con esto, Jorge Bergoglio desautoriza los planteamientos tomistas que durante un largo período de tiempo habían sido el marco de comprensión moral sobre el castigo capital. ${ }^{3}$

La intención de este estudio es hacer un recorrido diacrónico que nos permita ver las distintas posiciones que la Iglesia ha ido adoptando en su devenir temporal con respecto a la pena de muerte. Para ello partiremos de los datos ofrecidos por la Sagrada Escritura con la finalidad de comprobar qué aportaciones hace el dato revelado sobre esta temática. Continuaremos analizando el pensamiento del cristianismo primitivo sobre la misma cuestión para pasar en un posterior apartado al análisis reflexivo que se hizo en la escolástica con relación a la aplicabilidad de la pena máxima a un condenado. Finalmente, centraremos nuestra atención en el cambio de sensibilidad que se experimentó en el ámbito jurídico-penal y su inevitable influencia en la reflexión teológico moral que desembocó en la actual formulación del Magisterio.

\section{LA PENA DE MUERTE EN LA SAGRADA ESCRITURA}

Son varios los pasajes de la Escritura donde esta se pronuncia a favor de la aplicación de la pena capital. Ya en el primer libro de la Biblia, en el Génesis, encontramos una prescripción dada por Yahvé a Noé. Ante la corrupción de la humanidad Dios decidió enviar el diluvio para arrasar la tierra y recomenzar su obra a partir de la familia de Noé y de las distintas parejas de animales salvadas en el arca. Concluido el diluvio, Yahvé bendijo a su siervo y a sus descendientes entregándoles la tierra para que la gobernaran dejándoles como primer mandado legal el respeto a la vida siendo el castigo para todos aquellos que no lo hicieren la pena capital. Y así leemos lo siguiente:"Quien vertiere sangre humana, por otra persona será su sangre

3 Cf. Barret Turner, "Pope Francis and the Death Penalty: A Conditional Advance of Justice in the Law of Nations", Nova et vetera 4 (2018) 1041-1050: https:// doi.org/10.1353/nov.2018.0038; Luis Arroyo ZAPATERO - Luigi FoffanI, "La pena di morte nella Chiesa cattolica: la riforma del catechismo di papa Francesco", Quaderni di diritto e politica ecclesiastica 27 (2019) 45-55: https://doi. org/10.1440/95747. 
vertida, porque a imagen de Dios hizo Él al ser humano" (Gén 9,6). ${ }^{4}$ La sentencia es clara. El homicidio se presenta de este modo como motivo para ejecutar al malhechor.Y así aparece en otros pasajes de la Torá en los que se recoge la misma condena como por ejemplo en el libro del Éxodo en el que puede leerse que"si alguien se excita contra su prójimo y lo mata con alevosía, lo arrancarás de mi altar para matarlo" (Éx 21, 14). Sentencia condenatoria similar encontramos en el tercer libro de la Biblia cuando de manera concisa sostiene que"el que hiera mortalmente a cualquier otro hombre morirá" (Lev 24, 17). El cuarto libro de la Escritura se pronuncia en términos parecidos con respecto al delito de homicidio y así podemos leer entre sus páginas el siguiente texto:

Pero si le ha herido con un instrumento de hierro, y muere, es un asesino. El asesino debe morir. Si le hiere con una piedra con la que puede causarle la muerte, y muere, es un asesino. El asesino debe morir. Si le hiere con un instrumento de madera con el que puede matarle, y muere, es un asesino. El asesino debe morir. (...) Si el homicida lo ha matado por odio, o le ha lanzado algo con intención, y muere, o si por enemistad le ha golpeado con las manos, y muere, el que le ha herido tiene que morir: es un asesino. (Núm 35, 16-18.20-21a)

La sentencia por asesinato queda perfectamente establecida en esta cita que acabamos de presentar donde su autor describe los distintos instrumentos que se pueden utilizar para arrebatarle la vida a alguien. El asesinato es presentado, por tanto, como un crimen gravísimo al que le corresponde una condena severa. La legislación estipula la aplicación de la pena capital solo en el caso de que la agresión dirigida contra otro hombre dé como resultado la muerte de este, pues no todo acto violento dirigido contra un ser humano termina con el fallecimiento del mismo. Se puede seguir sumando textos, pero con los presentados tenemos más que suficientes para asentar esta base jurídica: que ciertos pasajes de la Sagrada Escritura prescriben la pena de muerte en los casos de homicidios. ${ }^{5}$ Es decir,

4 Esta y las siguientes citas que presentemos en este artículo están tomadas de la Biblia de Jerusalén, Bilbao, Desclée de Brouwer, 2019.

5 El homicidio no es el único delito por el que la legislación bíblica impone la pena capital. Hay otras acciones a las que les corresponde la misma sentencia condenatoria. Podríamos clasificar dichas acciones en tres grupos de infracciones. Un primer grupo relativo a los pecados sexuales y así tendríamos que se prescribe la 
si se le da muerte violenta a alguien se puede proceder de la misma manera contra el agresor. Esta mentalidad jurídica no es exclusiva de Israel sino de todos los pueblos de la antigüedad pues en ese período de la historia humana las sociedades se regían por el llamado régimen de venganza privada. Dios le permitió a su pueblo dirigirse durante un tiempo por este régimen. Pero el problema que este sistema acarreaba era que con mucha frecuencia la venganza excedía la afrenta sufrida. Se hacía necesario limitarla. Para ello se fueron desarrollando, con el transcurrir del tiempo, algunos mecanismos de control.

pena de muerte para casos de adulterio, tanto para la mujer como para el hombre (Lev 20,10; Dt 22,22); en casos de bestialidad, es decir, cuando un hombre o una mujer mantiene relaciones sexuales con un animal (Éx 22,18; Lev 20,15); cuando hay sexo prematrimonial con jóvenes comprometidas con otros varones (Dt 22, 13-21); en caso de relaciones homosexuales (Lev 20,13); cuando se confirma un incesto o un tipo de relación considerada antinatural (Lev 20,11-14); en caso de libertinaje o prostitución de la hija de un sacerdote (Lv 21,9) y en el supuesto de una violación de una mujer prometida (Dt 22,23-27). Otro grupo de delitos a los que les corresponde la pena suprema los podemos clasificar como acciones que atentan contra el honor de Dios y así tenemos la blasfemia (Lev 24,16); los casos de falsos profetas que hablan sin la autoridad de Yahvé (Dt 13,6; 18,20); en el pecado de idolatría (Lev 20,2; Dt 13,7-19; 17,2-7); en los casos de proselitismo hacia otras religiones; por romper la ley del descanso sabático (Éx 31,14; 35,2; Núm 15,32-36); y en los casos de hechicería, brujería o adivinación (Éx 22,17). El tercer grupo de delitos merecedores de la aplicación de la pena capital sería una miscelánea de casos como el de insubordinación a la autoridad del sacerdote o del juez (Dt 17,12); en casos de secuestro (Éx 21,16; Dt 24,7); en los casos en los que un hijo deshonre a sus padres, bien por golpearlos (Éx 21,15.17), bien por maldecirlos (Lev 20,9) o bien por desobedecerlos yendo contra la autoridad de su progenitor (Dt 21,18-21); los casos en los que se haya demostrado que un testigo haya testificado en falso en relación a un presunto delito que conlleve la pena capital (Dt 19,16-19). Aparte de esta casuística que hemos presentado existe otro caso particular en el que se decreta la muerte de toda aquella persona que toque el monte Sinaí cuando Yahvé esté dando las tablas de la ley a Moisés (Éx 19,10-12). Con esto se pretende introducir una enseñanza clara e inequívoca y es que debe existir una separación entre lo sagrado y lo profano. Precisamente por eso todos aquellos lugares en los que Dios pone su presencia son lugares de acceso prohibido. Esta idea es la que justifica la muerte de Uzá al tocar el arca de la Alianza (2 Sam 6,6-8). Como se ha podido ver, el homicidio no es el único caso por el cual la legislación bíblica decreta la pena máxima contra una persona, sin embargo, en este estudio nos centraremos sólo en la relación de esta pena con respecto al asesinato. Muchos de los casos atestiguados por la legislación judía eran compartidos por los pueblos circundantes. Sin embargo, las leyes hebreas no aplicaban la pena máxima ante los delitos cometidos contra la propiedad privada, algo que sí ocurría en los pueblos de su entorno. 
El primero de ellos fue la aparición de la llamada Ley del Talión. ${ }^{6}$ Sin duda fue un avance legal en las sociedades primitivas en tanto que se convirtió, desde su creación, en un mecanismo regulador del régimen de venganza privada tanto a nivel cuantitativo como cualitativo. Efectivamente, la expresión ojo por ojo y diente por diente, aunque pueda parecerle al hombre occidental del siglo XXI una aberración jurídica, lo cierto es que permitía que la acción vengativa no fuera más allá del daño recibido. No se puede poner en duda que en sociedades tan arcaicas como en aquellas que se regían por el régimen anteriormente descrito, la venganza no fuera ejercida a capricho y abusivamente. La misma formulación de esta ley ya recogía las dos regulaciones a las que hemos aludido. Y así tenemos que, en el plano cuantitativo, quien le hubiera sacado un ojo a su prójimo no era merecedor de que se le sacaran los dos. En este sentido, la misma ley imponía una cierta ecuanimidad. Lo mismo cabría decirse del plano cualitativo, por lo que, si alguien había causado la muerte de un animal de labranza a su vecino, este, en compensación, no podía ya apelar a su derecho de venganza para matarle a su hijo.

Aunque la Ley del Talión imponía un límite al ejercicio de la venganza todavía presentaba un resquicio para que esta se colara descontroladamente. El motivo de esto es que la venganza se ejecutaba personalmente, es decir, era el propio afectado quien se veía con la razón de reivindicar su "derecho" cercenado. E indudablemente, quien se venga, difícilmente puede evitar que la familia de aquel sobre quien haya recaído su vendetta hiciera lo mismo con respecto a él. Por tanto, la naturaleza de esta ley no era particular sino eminentemente social en la medida que se buscaba erradicar la espiral del mal dentro de la sociedad. En este sentido, surgió una nueva limitación a la vindicta de los pueblos primitivos, que fue la aparición de la figura del vengador de la sangre. Con esto lo que se pretendía era profesionalizar, de alguna manera, la aplicación de los castigos de tal modo que

6 El nombre de esta ley proviene del latín, Lex Talionis. El término latino tallos significa "semejante" o"idéntico". Por lo tanto, se trata de una ley en donde la pena a aplicar sea idéntica a la sufrida. Su formulación bíblica versa así:"[...] pagarás vida por vida, ojo por ojo, diente por diente, mano por mano, pie por pie, quemadura por quemadura, herida por herida, cardenal por cardenal" (Éx 21,23-25). Otros pasajes donde se recoge esta ley son: Lev 24,18-20; Dt, 19,21. Cf. Herbert Bardwell Huffmon, "Lex talionis”, in David Noel FreEdman (ed), The Anchor Bible Dictionary IV, New York, Doubleday 1992, 322. 
ya no era el individuo quien unilateralmente se arrogaba el derecho de vengarse de aquellos que le hubieran hecho algún mal, sino que ahora se recurría a una persona que era la designada para ejercer la venganza en nombre de todos aquellos pertenecientes a un clan. Este recibía el nombre de go'el y, generalmente, era el pariente más próximo a la víctima quien, dentro de una cultura eminentemente patriarcal, se constituía en el protector oficial. ${ }^{7}$ Pero para que se pudiera llevar a cabo esta acción de justicia retributiva, el ejercicio de la venganza se vio aún más limitado por la necesidad de introducir testigos que certificaran que la acción delictiva punible hubiera sido realizada por la persona acusada (Núm 30,19). Con esto se evitaba errar al aplicarle a un individuo la pena capital sobre todo por las falsas acusaciones que pudieran verterse contra alguien por parte de un tercero.

Sin embargo, aunque con estos recursos (introducción del go'el y la necesidad de acompañar la acusación con testigos) se consiguió mitigar los excesos de la venganza privada, quedaba todavía otra cuestión problemática que resolver que era la aplicación de la pena a una persona que hubiera causado involuntariamente la muerte a otra. En el ámbito del derecho penal se distingue claramente entre un asesinato realizado con premeditación y alevosía y un homicidio involuntario. Distinción nada baladí pues de ella va a depender el tipo de sentencia condenatoria. No podemos pedirles a los autores bíblicos una disección jurídica como la que podemos hallar en nuestro

7 Cf. Aurelio FERnÁNDEZ, Teología Moral II, 802-803. El vocablo go'el deriva del verbo hebreo gaal que alude a los diversos modos de ayuda a los demás componentes de una familia. Se trataría de una acción basada en la solidaridad entre los miembros de un mismo clan. De los textos veterotestamentarios podemos concluir que el go'el posee cuatro funciones. La primera es la que hemos expuesto en el cuerpo del artículo al presentarlo como el vengador de la sangre. Es decir, sería la persona encargada, en virtud de la Ley del Talión, de aplicar el castigo capital contra los victimarios de su familia. La segunda función es la de rescatar las tierras de sus familiares más cercanos cuando estas hayan sido vendidas o bien, enajenadas de acuerdo con la Ley del Jubileo (Lev 25.25). Una tercera función del go'el es hacer cumplir la ley del levirato para garantizar la descendencia y dar protección a la viuda. Finalmente, el goelato está también encargado de recuperar la libertad de aquellos miembros de la familia que la hayan perdido al venderse como esclavos. Se trataría de una acción vinculada estrechamente a la ley del año sabático (Lev 25,47-49). Cf. Xabier PiKAZA, Goel/Goelato, en Diccionario de la Biblia. Historia y palabra, Estella, Verbo Divino, 2007, 410. 
código penal con las distinciones entre atenuantes, agravantes o eximentes, pero sí intentaron marcar la diferencia entre el acto homicida voluntario e involuntario. ${ }^{8}$ Un texto clarificador de cuanto decimos es el siguiente:

Cuando Yahvé tu Dios haya exterminado a las naciones cuya tierra te va a dar Yahvé tu Dios, una vez que las hayas desalojado y habites en sus ciudades y en sus casas, te reservarás tres ciudades en medio de la tierra que Yahvé tu Dios te va a dar en posesión. Mantendrás abierto el camino de acceso a ellas, y dividirás en tres partes el territorio del país que Yahvé tu Dios te va a dar en posesión: esto para que todo homicida pueda refugiarse allí. Este es el caso del homicida que puede salvar su vida refugiándose allí. El que mate a su prójimo inadvertidamente, sin haberle odiado antes, (por ejemplo, si va al bosque con su prójimo a cortar leña y, al blandir su mano el hacha para talar el árbol, se le sale el hierro del mango y va a herir mortalmente a su prójimo), podrá refugiarse en una de esas ciudades para salvar su vida. De lo contrario el vengador de la sangre puede perseguir al asesino cuando el corazón le arda de ira, darle alcance por ser largo el camino y herirlo de muerte, siendo así que no era reo de muerte, puesto que no odiaba anteriormente al otro. [...] Pero si un hombre odia a su prójimo y le tiende una emboscada, se lanza sobre él, lo golpea hasta matarlo y luego se refugia en una de esas ciudades, los ancianos de su ciudad mandarán que vayan a detenerle allí y lo entregarán en manos del vengador de sangre, y morirá. (Dt 19 1-6.11-12).

El recurso consistente en designar ciudades de asilo dentro del territorio de Israel supuso un nuevo mecanismo de control de la venganza privada. El go'el, aunque tuviera la autoridad moral recibida por su clan para ejercer la vindicta, no podía ejercerla dentro de los límites de las polis reservadas. Estas actuaban de refugio para aquellas personas que hubieran causado accidentalmente la muerte de su prójimo. Su estancia, por tanto, en estas poblaciones servía para clarificar el asunto racional y pausadamente evitando de este modo una actuación pasional como producto de la ira emergida ante un presunto homicidio todavía no demostrado.

8 Algunos autores han señalado los intentos por parte de los escritores bíblicos de marcar las diferencias entre atenuantes y agravantes con relación a ciertos delitos. Cf. Francisco Varo, “Elementos antropológicos y éticos en el derecho penal de la Biblia Hebrea", Revista de estudios históricos-jurídicos 42 (2020) 78-79: http:// dx.doi.org/10.4067/S0716-54552020000100067. 
Así pues, a tenor de lo que los textos veterotestamentarios nos aportan podemos afirmar que la pena capital era algo admitido por el pueblo de Israel si bien es verdad que ha habido una cierta evolución en cuanto a su aplicación, evolución que ha estado enfocada en su mitigación con la única finalidad de ir controlando el ejercicio de la venganza para que esta ni fuera excesiva, manteniéndose así una justa proporcionalidad entre delito y pena, ni tampoco fuera injusta puesto que existía la posibilidad de inculpar y ejecutar a un inocente.

Pero, si el Antiguo Testamento presenta abiertamente esta aceptabilidad de la pena capital, el Nuevo Testamento se ha guardado de manifestarse sobre esta temática. De hecho, no se trata de una cuestión que esté presente en la enseñanza de Jesucristo ni en la predicación apostólica propiamente dicha. Es más, si la justificación de la pena de muerte en el Antiguo Testamento tenía como basamento la Ley del Talión, vemos como en el Nuevo Testamento es esta misma ley la que Cristo se encargó de abolir en el Sermón del Monte (Mt 5,38-42). La venganza ya no tiene cabida en la nueva propuesta de relaciones humanas manifestada por el Galileo ya que queda diluida en el precepto nuevo de la caridad que postula llevar el amor hasta los enemigos.

Aunque no hay textos explícitos que condenen la pena capital, una lectura pausada de las páginas neotestamentarias nos lleva a concluir que esta no formaba parte del ideario evangélico. Basta simplemente con asomarse a las posturas adoptadas por Cristo o los apóstoles ante casos contemplados por la legislación antigua en los que sí merecería tal castigo. Como ejemplo de esto tenemos la actitud del Nazareno ante la mujer adúltera que le fue presentada para que fuera sentenciada a muerte por su acción adulterina. Sin embargo, el evangelista san Juan recoge a la perfección la enseñanza del Maestro al condenar el pecado, pero no a la pecadora; con lo que salía al paso del reto de los escribas y fariseos, tan apegados a las tradiciones y grandes conocedores de la legislación de la Torá, la cual sí prescribía la lapidación para este tipo de comportamientos (cf. Jn 8,1-11). ${ }^{9}$

Aunque el texto de la mujer adúltera se encuentra ubicado en el cuarto evangelio, son muchos los exégetas que consideran que este pasaje no pertenece a san Juan. De hecho, los manuscritos más antiguos de este evangelio (los papiros 66 y 75, el códice Sinaítico, Vaticano, etc.) no recogían esta perícopa. El Bezae Cantabrigensis es el primero que la recoge en el siglo v. Pero que la perícopa 
Los apóstoles tampoco disertaron en sus discursos sobre la cuestión de la pena capital. Ellos se limitaron a la predicación kerigmática que era lo que urgía dadas las circunstancias de la naciente Iglesia. Tampoco el apóstol Pablo deja ninguna noticia concreta sobre el tema, aunque algunos teólogos y juristas suelen traer a colación un texto suyo para justificar la pena de muerte:

Que todos se sometan a las autoridades establecidas, pues no hay autoridad que no provenga de Dios, y las que existen, por Dios han sido constituidas. De modo que, quien se opone a la autoridad, se resiste al orden divino, y los que se resisten se están buscando ellos el castigo. En efecto, no hay por qué temer a los magistrados cuando se actúa correctamente, sino cuando se comete alguna fechoría. ¿Te gustaría vivir sin miedo a la autoridad? Pues actúa correctamente, y obtendrás de ella elogios. Piensa que es un servidor de Dios para tu bien. Pero, si cometes alguna fechoría, tienes razones para temer, pues no en vano lleva la espada. Piensa que es un servidor de Dios para hacer justicia y castigar al que hace algo malo. Por tanto, es preciso someterse, no sólo por temor al castigo, sino también en conciencia. Por eso precisamente pagáis impuestos, porque son funcionarios de Dios, ocupados en ese oficio. Dad a cada cual lo que se le debe: a quien impuestos, impuestos; a quien tributo, tributo; a quien respeto, respeto; a quien honor, honor. (Rom 13,1-7).

En este pasaje, el de Tarso exhorta a los romanos creyentes a obedecer a la autoridad civil y a hacerlo, al menos por temor, ya que posee el llamado ius gladii. Pero, ¿está con ello justificando o defendiendo el derecho a poder aplicar a los ciudadanos la pena capital ante ciertas acciones delictivas? La historia de la exégesis nos lleva a responder negativamente a la pregunta planteada. De hecho, durante el primer milenio del cristianismo los grandes comentaristas

pertenezca o no al corpus joánico en nada invalida la argumentación presentada ya que se trata de un texto que la tradición ha recibido como inspirado, en el que se recoge a la perfección la actitud de Jesús con relación al rechazo de la pena máxima. Cf. Hernán Sevillano Castillo, "¿Quién te ha condenado? La mujer adúltera: justicia y misericordia", Albertus Magnus 2 (2017) 310313: https://doi.org/10.15332/25005413/4724. Cf. Pheme PERKINS, "Evangelio de Juan", en Raymond E. Brown - Joseph A. FitzMYER - Roland E. Murphy (eds.), Nuevo Comentario Bíblico San Jerónimo. Nuevo Testamento, Estella, Verbo Divino, 2004, 558; y, con mucha bibliografía, Chris KeITH, "Recent and Previous Research on the Pericope Adulterae (John 7.53-8.11)", CBR 6 (2008) 377-404: https://doi. org/10.1177/1476993X07084793. 
bíblicos no pensaron que Pablo estuviera reivindicando el derecho de los gobernantes a aplicar la pena de muerte. Esta es más bien una lectura que se hace a partir del siglo XII por algunos juristas y teólogos con la finalidad de afianzar la idea de la pena capital. Hasta la citada centuria, los intérpretes bíblicos apuntaban a que la intención de Pablo con este texto era inocular en los creyentes de su comunidad la obediencia y el acatamiento al poder coactivo del Estado pues entendía que las circunstancias históricas y socio-políticas aconsejaban precisamente esto para evitar amenazas y ataques innecesarios que pusieran en peligro la vivencia de la nueva fe así como su propagación. ${ }^{10}$ En apoyo de esta interpretación está la actitud y la enseñanza del apóstol de los gentiles expresadas en otras partes de sus cartas. Así tenemos que ante la notificación que le llegó de que entre los cristianos de Corinto había un caso de unión incestuosa que estaba causando escándalo entre los creyentes conminó a los miembros de esa comunidad a que procedieran a expulsar de la misma al implicado (1 Cor 5,1-13). El hecho es significativo con relación a la cuestión que estamos tratando pues el incesto era uno de los motivos por los cuales se prescribía la pena capital según la ley judía. Sin embargo, Pablo no alude a ella para argumentar en su favor, sino que propone la excomunión y, no la muerte, como castigo por la acción cometida.

En esta línea se sitúa de nuevo cuando le recuerda también a esa misma comunidad que "ni impuros, ni idólatras, ni adúlteros, ni afeminados, ni homosexuales, ni ladrones, ni avaros, ni borrachos, ni explotadores heredarán el Reino de Dios" (1 Cor 6,9b-10). Si comparamos esta lista de pecados con las acciones que en el Antiguo Testamento se consideran merecedoras de muerte, vemos que hay muchas que coinciden. Sin embargo, no se hace ninguna mención

10 "Los expositores de la Iglesia primitiva hasta el siglo XII encontraron en el símbolo de la espada únicamente el poder coactivo del Estado. Los exégetas desde el siglo XII hasta el XIX, en la espada vieron el símbolo de la pena capital, aunque no faltaron excepciones. Los actuales se dividen en ambas teorías. San Pablo no pretendió otra cosa que inculcar en los fieles la obediencia al poder coactivo del Estado no sólo por obligación de conciencia sino por temor al castigo. Todo lo demás es disquisición de partido sin garantía de autoridad revelada. Los intérpretes hasta el siglo xII, así lo entendieron sin una sola excepción. Esto es necesario y bastante para sostener el valor de revelación contra la pena capital": Luis Vecilla, "Ordenamiento divino de la vida humana", Revista Española de Derecho Canónico 14 (1959) 64. 
a la pena capital. Si el apóstol Pablo tenía entre sus líneas magisteriales la justificación de la pena máxima, ¿por qué dejó pasar la oportunidad de aludir a ella ante los casos anteriormente expuestos? Simplemente se limita a decir que tales acciones son incompatibles con la fe en Cristo y cuya sanción está reservada para la otra vida, pero, para esta, no especifica ninguna pena. Evidentemente, este cambio de mentalidad que se produjo en Pablo al pasar de ser fariseo a ser apóstol está inexorablemente unido a la enseñanza del Galileo. La doctrina moral de Cristo y su propio ejemplo muriendo en la cruz mientras perdonaba a sus verdugos fueron tan revulsivos para sus seguidores que ninguno de ellos se atrevía a apelar a la pena de muerte para castigar a los malvados, pues con ella no se daba cabida al perdón incondicional ofrecido por un Dios que no busca la muerte del pecador, sino que se arrepienta y viva.

El arrepentimiento es la clave explicativa por excelencia de la total ausencia de un corpus legislativo en el Nuevo Testamento con respecto a la aplicación de la última pena. Pero esta concepción del arrepentimiento no surge repentinamente en los textos neotestamentarios, sino que hunde sus raíces en el PrimerTestamento. Es verdad que en ciertos pasajes de la Antigua Alianza podemos encontrar, tal y como se han presentado unas páginas más arriba, determinadas disposiciones penales para aplicar el castigo capital. Sin embargo, es justo resaltar que existe en la Torá lo que algunos autores han denominado"el discurso correctivo de la ley". ${ }^{11}$ Con esto lo que se pretende es poner de manifiesto que la intención última de la legislación no era la venganza o el castigo, sino la corrección orientada a favorecer el arrepentimiento $y$ es en este contexto donde hay que leer los textos presentados. De hecho, así se desprende de la actitud de Yahvé con relación a algunos personajes de la Antigua Alianza cuyas acciones hubieran merecido la aplicación de la condena a muerte, según la tipificación penal hebrea, como es el caso del fratricidio de Caín que bien hubiera merecido la sentencia más dura por su delito como era la pérdida de la vida. Sin embargo, el castigo que Dios le aplicó fue el exilio y, además, signándolo para que nadie lo tocara (cf. Gén 4,11-15). Lo mismo se podría decir del relato del diluvio pues desde que este es anunciado hasta que se ejecuta transcurre un período de siete días, algo que bien puede ser

11 Cf. Massimo Grilli, “La pena di morte alla luce del pensiero biblico sulla giustizia", Gregorianum 88/1 (2007) 71. 
interpretado como un tiempo de gracia ofrecido por Dios para favorecer la conversión (cf. Gén 7,4). Con esto se ve que Dios castiga, pero dejando lugar para la esperanza. Esa esperanza fue profundizada por los profetas y llegó con fuerza hasta las páginas del Nuevo Testamento. Por eso, para la Nueva Alianza, la pena capital era ya algo completamente ajeno a la voluntad divina.

¿Hasta dónde alcanzó el influjo de esta enseñanza neotestamentaria? A responder a esta pregunta dedicamos los dos próximos apartados de este estudio. Comencemos ahora con el primero de ellos.

\section{LA CONSIDERACIÓN DE LA PENA DE MUERTE EN LOS PRIMEROS SIGLOS DEL CRISTIANISMO}

El cristianismo primitivo vivió fuertemente influenciado por dos fenómenos que lo llevaron a rechazar frontalmente y sin ambages la pena capital aun siendo esta una tipificación penal de gran raigambre en el Derecho Penal Romano. El primero de ellos era de tipo doctrinal y es que no se debe soslayar que los primeros cristianos se vieron atraídos por el mensaje novedoso de un Galileo que no solo había predicado el amor a los enemigos y había hecho de la misericordia y el perdón sus pilares, sino que Él mismo había dado ejemplo al obrar así con respecto a aquellos que lo condenaron. No era para los primeros creyentes una cuestión insustancial el ser conscientes de que aquel en quien creían y consideraban como el Hijo de Dios había muerto como resultado de la aplicación de una pena de muerte. Aquí había dos cuestiones a considerar. La primera es que la muerte del malhechor supone no haber practicado con él el perdón por los delitos cometidos. La ejecución no permite la conversión. Y la segunda es que si el Nazareno fue condenado a muerte siendo inocente es porque el derecho no siempre acierta en su discernimiento entre inocentes y culpables. Esto último se vio subrayado con el segundo de los fenómenos al que aludíamos anteriormente que es de carácter histórico. Sabido es que durante los primeros cuatro siglos los cristianos vivieron bajo sangrientas persecuciones y tuvieron que contemplar como muchos de sus hermanos en la fe eran condenaos a muerte precisamente por creer en el Resucitado. ${ }^{12}$ Este hecho contri-

12 Cf. Jorge CuESTA FERNÁNDEZ, "El cristianismo primitivo ante la civilización romana. Sobre la imagen como persecutores christianorum de Nerón y Domiciano a través 
buyó enormemente al rechazo a la pena capital, que fue considerada abiertamente contraria a las enseñanzas cristianas.

La incompatibilidad entre la nueva fe en Jesús de Nazaret y los atentados contra la vida humana pronto se pusieron de manifiesto. Un ejemplo de esto lo tenemos en Hipólito de Roma quien en la Traditio Apostolica deja las siguientes sentencias en relación con algunas profesiones:

[...] No proseguirá ni será admitido el gladiador, el que enseña a luchar a los gladiadores, el que lucha con los animales en la arena o el que tiene a su cuidado los juegos de gladiadores. [...] El soldado que haya recibido la orden de hacerlo, no matará a nadie. Si se lo mandan, que no ejecute la orden ni preste juramento. Si rehúye hacerlo así, que no sea admitido. No proseguirá o que sea expulsado el que tiene el poder de la espada o el magistrado de la ciudad que viste de púrpura. El catecúmeno o el fiel que quieren ser soldados serán expulsados, porque han despreciado a Dios. ${ }^{13}$

El número 16 del documento citado recoge un conjunto de oficios que son irreconciliables con el seguimiento a Cristo. Nosotros hemos querido centrarnos solo en aquellos que suponen un atentado contra la vida humana como es el del gladiador, el del soldado o el de juez. ${ }^{14}$ De estas tres profesiones, esta última entronca perfectamen-

de las primitivas fuentes cristianas", Antesteria 1 (2012) 127-141; Raúl GonZÁLEZ SALINERO, Las persecuciones contra los cristianos en el Imperio Romano, Madrid, Signifer Libros, 2005.

13 Hipólto de Roma, La Tradición Apostólica, n. 16, en Cuadernos Phase 75 (1996) 33.

14 Los cristianos en general y los catecúmenos en particular tenían el deber moral de abstenerse de participar en las luchas de gladiadores, de ofrecer culto al emperador o de cumplir órdenes tanto de las autoridades judiciales como militares que conllevaran dar muerte a un ser humano. No podían hacerlo ni como soldados ni como simples actores ejecutores de la ley. Cf. Niceto BlázQuez, La pena de muerte, Madrid, San Pablo, 1994, 17-18. Para un mayor conocimiento de la actitud, el comportamiento y el modo de pensar de los primeros cristianos con respecto a la violencia ejercida por el Estado véase Jean-Michel Hornus, Evangelie de Labarum. Étude sur l'attitude du christianisme primitif devant les problèmes de l'Etat, de la guerre et de la violence, Genève, Éditions Labor et Fides, 1960. Tertuliano, una vez convertido al cristianismo también se opondrá a los espectáculos públicos y argumentará contra su licitud moral por cuanto en ellos se aprecia una violencia clara contra la vida humana, algo indigno de un cristiano, de ahí que abogue para que estos no participen de semejantes "pompas del Diablo" tal y como él mismo las cataloga. Cf. Tertuliano, De spectaculis, 19. Sobre la posición adoptada por Tertuliano y por el cristianismo primitivo frente a espectáculos violentos dentro 
te con la temática que estamos debatiendo."El poder de la espada", idea que ya está presente en la carta a los Romanos, nos aparece de nuevo aquí aludiendo al ius gladii que poseen los magistrados en función de su cargo como administradores de justicia. Estos, en su misión de mantener el orden y el bien común, deben emitir sentencias condenatorias en los casos establecidos por el derecho. Como jueces deben cumplir y hacer cumplir las leyes, pero como cristianos deben negarse a condenar a un hombre a muerte, aun siendo culpable. Esto coloca a quienes ostentan estos cargos en una disyuntiva: o su fe o su profesión. Ambas son incompatibles.

En la misma línea argumentativa se sitúa otro de los promotores de la no violencia del paleocristianismo como fue el africano Lactancio. En su obra Divinae Institutiones nos deja escrito lo siguiente:

Los que se esfuerzan por seguir el camino de la justicia no deben asistir ni participar en estos crímenes públicos y es que, cuando Dios nos prohíbe matar, no sólo nos prohíbe hacer estragos cosa que no está permitida ni siquiera en las leyes públicas, sino que nos aconseja que no hagamos incluso cosas que son lícitas entre los hombres. Así el justo no deberá servir en la milicia, ya que su milicia es la propia justicia, ni provocar una acusación capital contra nadie, ya que no hay diferencia entre matar a alguien con la espada y matarlo con la palabra: y es que lo que está prohibido es el crimen en sí, de forma que en este concepto divino no hay que hacer ninguna distinción: siempre será crimen matar a un hombre, del que Dios quiso que fuera un animal sagrado. ${ }^{15}$

del Imperio Romano véase Miguel Ángel BetANCor LEÓN - Germán SANTANA Henríquez - Conrado Vilanou Torrano, De Spectaculis. Ayer y hoy del espectáculo deportivo, Madrid, Universidad de Las Palmas de Gran Canaria - Ediciones Clásicas, 2001.

15 "Huius igitur publici homicidii socios et participes esse non conuenit eos qui iustitiae uiam tenere nituntur. Non enim cum occidere deus uetat, latrocinari nos tantum prohibet, quod ne per leges quidem publicas licet, sed ea quoque ne fiant monet quae apud homines pro licitis habentur. Ita neque militare iusto licebit, cuius militia est ipsa iustitia, neque uero accusare quemquam crimine capital, quia nihil distat utrumne ferro an uerbo potius occidasm quoniam occisio ipsa prohibetur. Itaque in hoc dei praecepto nullam prorsus exceptionem fieri oportet, quin occidere hominem sit semper nefas, quem deus sacrosanctum animal esse uoluit": Lactancio, Divinae Institutiones, Libro VI, 20, 15-17. Hemos querido poner en cursiva la expresión "sacrosanctum animal" porque se trata de un Hapax dentro de los textos de Lactancio. En el texto citado el africano ha querido con toda la intención del mundo vincular la palabra sacrosanctum al término nefas para subrayar de este modo la inviolabilidad de la vida humana. El poeta romano 
La concepción sacrosanta que Lactancio tiene del ser humano lo lleva a ser, no solo un claro opositor de la pena de muerte, sino de todas aquellas prácticas, acciones u oficios que puedan atentar contra la vida humana. De ahí que estemos ante un pensador que considera que en el quinto mandamiento del decálogo nos encontramos ante una prohibición absoluta y que ninguna circunstancia podría justificar una acción dirigida contra la vida de un hombre con total independencia de los delitos cometidos. Un crimen no se limpia con la ejecución de otro como es la pena de muerte.

Estaba calando en el tejido social y espiritual del cristianismo primitivo la incompatibilidad entre la pena de muerte y la fe en el Galileo. Una incompatibilidad que cuestionaba abiertamente, como hemos expuesto, ciertos oficios, entre ellos el de juez. Se trató de una cuestión tan sumamente importante que ya el primer concilio de la Hispania Romana, el de Elvira, celebrado a principios del siglo $\mathrm{IV}^{16}{ }^{16}$ recogía en uno de sus cánones la prohibición de que los jueces entraran en la Iglesia. Mandar matar a alguien y profesar la fe en Jesucristo eran realidades irreconciliables por más que aquel a quien se ejecutaba hubiera cometido los crímenes más execrables que pudieran imaginarse. ${ }^{17}$

Sobre el oficio de magistrado se pronuncia también san Ambrosio de Milán quien en una de sus epístolas nos deja por escrito que todos aquellos que en virtud de su cargo deban imponer la pena de muerte a un ciudadano por un delito cometido deben abstenerse voluntariamente de la comunión. Esta abstención realizada en libertad no solo no implica en modo alguno el apartamiento de la Iglesia, sino que

Publio Ovidio Nasón en su célebre obra Las Metamorfosis emplea una expresión similar a la de Lactancio al presentar al ser humano como sanctius his animal con la intención de presentar al hombre como plenitud, apoteosis y apogeo del cosmos según los postulados del estoicismo. Sobre esto último véase la nota 10 de Hernán Giudice, "Argumentos racionales y bíblicos sobre la pena de muerte en la patrística", Teología y vida 52 (2011) 307-322: http://dx.doi.org/10.4067/ S0049-34492011000100017.

16 Es difícil precisar la fecha exacta del Concilio de Elvira. De hecho, se trata de una cuestión bastante discutida por los historiadores y no hay un consenso mayoritario por lo que se suele dar la horquilla que va del año 300 al 324. Cf. Mario LORENTE MUÑOZ, "El Concilio de Elvira: introducción al estudio del primer testimonio eclesiástico del siglo iv en Hispania (análisis interno de la fuente y comentario de algunos cánones)", La Razón Histórica 45 (2020) 141.

17 "Magistratus vero uno quo agit dumviratum, prohibendum placet ut se ab Ecclesia cohibeat": Can. LVI. 
además viene acompañada por una alabanza del resto de los miembros de la comunidad. ${ }^{18}$

Como se puede ver la posición de la Iglesia sobre esta cuestión es firme, la vida humana merece respeto por sí misma y no se puede actuar contra ella ni siquiera en los casos contemplados por la ley. Esta postura, aunque sólida y generalizada, no ha sido unánime en el cristianismo primitivo. Es cierto que ha habido voces discordantes, pero en conjunto, la Iglesia primitiva se caracterizó por su defensa de la vida y su rechazo a la aplicación de la pena capital. ${ }^{19}$ Hay quienes han sostenido que con la consagración del cristianismo como religión oficial dentro del Imperio, la consideración de la Iglesia con respecto a la pena de muerte se fue relajando hasta el punto de justificar teológicamente las leyes que regulan la aplicación de esta sanción. Incluso se ha presentado la figura de san Agustín como el punto de inflexión en este proceso de aceptación paulatina del máximo castigo. ${ }^{20}$ Creemos que esto último es debido a una mala interpretación de los escritos agustinianos. A veces se ha hecho una lectura incorrecta de ciertos pasajes que han sido tomados fuera del contexto sociológico en el que fueron redactados. ${ }^{21}$ Sobre esta cuestión, conviene no perder de vista que los textos polémicos del obispo de Hipona con respecto a la temática de la pena capital pueden ser clasificados en tres bloques. El primero de ellos no son más que comentarios bíblicos al Antiguo Testamento donde simplemente se hace un análisis descriptivo de hechos consumados, pero sin que eso

18 "Nam sunt extra Ecclesiam tamen, qui eos in communionem non vocent sacramentorum coelestium, qui in aliquos capitalem sententiam ferendam aestimaverunt. Plerique etiam sponte se abstinent: et laudantur quidem...": SAN Ambrosio de Milán, Epístola 25 (PL 16,1084).

19 Sobre las opiniones de aquellos que sí aceptan la aplicación de la pena de muerte por parte de los jueces véase Michel SPANNENT, Tertullien et les premiers moralistes africains, Gembloux, Duculot 1969.

20 Entre los moralistas españoles que defienden esta idea tenemos a Aurelio Fernández. Cf. Teología Moral, II, 805-806.

${ }^{21}$ Para el obispo africano, el castigo debe estar siempre comprendido dentro de unos límites y sin duda alguna, la muerte implica sobrepasarlos. El pensamiento del Hiponense con respecto a la pena de muerte debe ser entendido dentro de su contexto socio-cultural. En este sentido no podemos perder de vista que estamos ante un pensador que se encontraba inmerso en una espiral de violencia causada por el paganismo y el donatismo. 
implique su aprobación. Un segundo conjunto de textos conflictivos lo constituyen aquellos que son una concesión a la legalidad vigente, "es decir, de textos en los que se expone el contenido de las leyes en vigor, sin que la descripción signifique aprobación de lo narrado". ${ }^{22} \mathrm{Y}$ el tercer grupo tiene que ver con los casos de muertes involuntarias, es decir, cuando lo que se busca no es provocar la muerte del otro de un modo directo sino defender la propia vida. Estaríamos, por tanto, ante casos de legítima defensa que no tienen absolutamente nada que ver con el tema de la pena de muerte.

Como hemos indicado, la inadecuada comprensión de estos escritos ha llevado a algunos a sostener que el de Hipona estaría a favor de la aplicación de la pena capital y que a partir de la defensa de la misma el Magisterio fue asumiendo una postura permisiva primero y defensiva después. Nada más lejos de la realidad. Ni el hiponense brindó aval alguno a la pena máxima ni el Magisterio inmediatamente posterior a él lo hizo. El corpus literario agustiniano no solo presenta textos conflictivos en cuanto a su interpretación con relación a la pena de muerte como ya hemos evocado más arriba, sino que también nos ofrece otro conjunto de escritos en los que se puede examinar y vislumbrar cuál era la verdadera postura del de Tagaste. Estos son los denominados textos deprecativos. ${ }^{23}$ Se trata de escritos, fundamentalmente sermones y cartas, en los que en un estilo parenético y con una impronta marcadamente pastoral se opone a toda penalización jurídica que implique cercenar la vida de un ser humano. Cuestión esta del todo relevante, sobre todo si tenemos en cuenta que san Agustín, en cuanto que obispo, se encontraba en una situación en la que tenía que defender a los católicos de los ataques y crímenes cometidos contra ellos tanto por parte de los paganos como por parte de los donatistas. Sin embargo, aun teniendo a su favor la existencia de leyes penales que establecían duros castigos para quienes se atrevieran a cometer delitos graves, el de Hipona actuaba como intercesor de aquellos que habían incluso asesinado a correligionarios suyos, pidiendo para ellos penas alternativas a la ejecución recordando que la dignidad humana del criminal no queda diluida o eliminada por el crimen execrable cometido. En este sentido

22 Blázquez, Pena de muerte, 27.

23 Cf. Niceto BlázQuez, La pena de muerte según San Agustín, Madrid, Ediciones Augustinus Revista, 1975, 143-170. 
distingue entre la naturaleza de la persona y la acción delictiva cometida recordando que la primera es obra de Dios mientras que la segunda es obra del hombre. Solicita, por tanto, represión para el delito perpetrado, pero respeto a la vida del delincuente. Un bello ejemplo de esto es la correspondencia epistolar entre Nectario y nuestro prelado. Ante los gravísimos hechos acaecidos en Calama, una antigua población del norte de África que vendría a ser la actual Guelma argelina, en la que los paganos apedrearon templos cristianos e incluso dieron muerte a algún que otro eclesiástico, Nectario, para interceder por los paganos implicados en el altercado, le escribe una carta a san Agustín apelando a su condición de obispo para que tenga misericordia con aquellos que han sido identificados como los autores materiales de los incidentes..$^{24} \mathrm{El}$ representante pagano reconoce que los autores de los hechos merecen la aplicación del código penal por parte de las autoridades civiles y que el corpus legislativo contempla la pena de muerte para los delitos acaecidos, pero apela a la caridad cristiana para que el representante de los damnificados actúe con benevolencia intercediendo ante los magistrados de la ciudad a los que les corresponde, en virtud de su oficio, aplicar las leyes vigentes. ${ }^{25}$

24 Se trata de una carta breve escrita en el verano del año 408, en la que Nectario pide al prelado su intercesión para que los magistrados suavicen sus condenas y no se moleste a los inocentes. Como compensación a la mitigación de las sentencias el representante pagano acepta la restitución material de los daños ocasionados por sus defendidos. El autor de la epístola se expresa en la última parte de la misma en estos términos “[...] In Calamensi colonia multa sunt quae merito diligamus; vel quod in ea geniti sumus, vel quod eidem magna contulisse videmur officia. Haec ergo, domine praestantissime et merito suscipiende, non levi populi sui erratu prolapsa est. Quod quidem si juris publici rigore metiamur, debet plecti severiori censura. Sed episcopum fas non est, nisi salutem hominibus impertire, et pro statu meliore causis adesse, et apud omnipotentem Deum veniam aliorum meriri delictis. Quamobrem quanta possum supplicatione deposco, ut si defendenda res est, innoxius defendatur, ab innocentibus molestia separetur. Praesta hoc quod secundum naturam tuam pervides postulari. De damnis facilis potest haberi taxatio; tantum supplica deprecamur. Acceptior Deo vivas, domine insignis et merito suscipiende frater": Epístola 90 (PL 33,313).

25 San Agustín entiende que el castigo social que se le deba aplicar a alguien por sus acciones delictivas debe tener unos límites. Pero, ¿quién garantiza esto? El de Tagaste considera que es necesario que el obispo asuma este papel de control intercediendo por los acusados. Ya existía algo parecido con la presencia del defensor del reo, pero el hiponense quería ir más allá con la figura del intercesor. Sobre esta cuestión un autor español ya citado se expresa así:"Para su efectividad 
El de Hipona responde pausadamente a su interlocutor con otra epístola escrita unos dos meses después. Lo hace con un texto más largo en el que explica la importancia social y correctiva del castigo, motivo por el cual no se puede dejar impune el delito cometido. Pero en la misiva compromete su palabra para garantizar que el castigo no fuera más allá de los límites que el respeto a la vida merece. Efectivamente, aunque el código civil preveía penas de muertes para las acciones delictivas acontecidas en Calama, el de Tagaste se compromete a interceder ante los jueces para que no sea la pena capital la sanción condenatoria para los paganos calamitas. ${ }^{26}$ No fue este un caso aislado, sino que se trataba de una práctica común en el episcopado de san Agustín. El prelado solicitaba siempre represión para el delito, pero de igual modo deprecaba sin descanso el respeto incondicional para la vida del delincuente. En este sentido no se cansó jamás de pedirle a los magistrados que hicieran todas las piruetas legales posibles para que no se aplicara la pena de muerte a los acusados. Es cierto que no atacó intelectualmente las leyes establecidas exigiendo la abolición de la pena capital, pero en la práctica la consideraba como una normativa que no debía imponerse. Abogó siempre por otras alternativas punibles que pudieran sustituir a la máxima sanción tales como la pérdida de la libertad, la confiscación de bienes o multas económicas. Pero incluso con estas alternativas se mostraba condescendiente, benévolo y caritativo pues velaba por que las sanciones confiscatorias no pusieran a los reos en una situación de

práctica San Agustín introduce la figura jurídica de la intercesión episcopal como réplica al clásico defensor del reo. La función del intercesor no consiste, según san Agustín, en cubrir o disimular los delitos del acusado, sino en contribuir a que la evidencia de los mismos resplandezca en toda su pureza objetiva, para que resalte más el sentido de humanidad mediante la mitigación de las penas y hasta el perdón completo del reo cuando se lo juzgue oportuno. El intercesor episcopal salva así todos los postulados de la justicia, de la misericordia y de la humanidad. El defensor, en cambio, [...], sólo se ocupa de la impunidad del reo, aun a costa de falsear y hasta negar conscientemente sus delitos. Con lo cual rinde un pésimo servicio a la causa de la justicia. Así, pues, hablando en general, San Agustín concibe al hombre como un ser socialmente punible por su capacidad radical de prevaricar, si bien dentro de unos límites que ninguna potestad humana puede sobrepasar": BlázQuEz, Pena de muerte, 24-25.

26 Cf. Epístola 91 (PL 33,313-318). La carta posiblemente fuera escrita en agosto del año 408. Cf. BlázQuez, La pena de muerte según San Agustín, 144. 
precariedad tal que se vieran abocados a la muerte por falta de recursos para su subsistencia.

Pero, si la praxis agustiniana era esta y además venía fundamentada por su profunda convicción del valor absoluto de la vida humana, ¿por qué no negó doctrinalmente la pena de muerte ni trabajó por su derogación jurídica? La respuesta a la pregunta estriba en el valor pedagógico que el de Hipona le daba a la ley. Su contexto social fue muy convulso, pues los católicos estaban inmersos en una espiral de violencia que tenía dos frentes bien localizados. Uno de ellos era el mundo pagano que se encontraba ya inmerso en un irrefrenable proceso de delicuescencia y el segundo era el frente surgido dentro de las filas mismas del cristianismo como fue la corriente sectaria del donatismo. Dentro de la secta donatista existía una rama especialmente belicosa como fue la de los circunceliones cuyo modus operandi consistía en asaltar y saquear granjas y villas de los católicos cometiendo no solo el delito del robo sino también el de asesinato. Esta ola delincuencial apenas podía ser reprimida por las autoridades encargadas de velar por el orden público. Lo único que había para frenarlos era la ley cuya dureza podía actuar como elemento disuasorio ante potenciales acciones de violencia. Por este motivo, san Agustín no quiso argumentar contra la existencia de las penas jurídicas dirigidas a cercenar la vida de un ser humano, no por convicción, sino por necesidad social.

Precisamente contra los donatistas volvemos a encontrar en el obispo africano su carácter reconciliador ya que su sentido cristiano de la justicia lo llevaba a interceder incluso por aquellos que perseguían de un modo directo a los católicos hasta darles muerte. El donatismo se había convertido en un problema no solo religioso sino también social y político. ${ }^{27}$ Los desórdenes públicos que estaban causando llevaron al emperador Honorio a enviar un rescripto al procónsul Donato para que reprimiera a esta secta con severidad haciendo uso de la ley en su máxima expresión y aplicando, si fuese necesario, la pena de muerte. ${ }^{28}$ San Agustín era conocedor de la misión que

27 Cf. Carlos García Mac GaW, "El donatismo: ¿religión o política?", Gerión 12 (1994), 133-154; IDEM, “Elementos políticos en el discurso teológico agustiniano. El caso del bautismo en la polémica con el donatismo", Anales de Historia Antigua, Medieval y Moderna 31 (1998) 9-27.

28 Cf. BlázQuez, La pena de muerte según San Agustín, 152. 
tenía Donato, en su condición de procónsul, de velar por la paz de la sociedad, y que tenía el encargo imperial de ser severo en el cumplimiento de las leyes. Por eso le escribe una misiva en la que, apelando a su condición de cristiano, no busque la venganza en la aplicación de las leyes sino el corregir y enderezar al que ha errado. Para el de Hipona, la ley debe ser correctora, no vengadora. La segunda parte de la carta recoge a la perfección el sentir y la intención del prelado. Por su belleza e importancia la reproducimos:

Te ruego, pues, que, cuando asistas a los pleitos de la Iglesia y veas que se le ha hecho objeto y víctima de graves injurias, olvides la potestad que tienes de matar y no olvides esta mi petición. No te parezca ruin e indigno, hijo honorable y dilectísimo, el que yo te pida que no los mates, pues pido al Señor que se corrijan. Además, no debemos nunca separarnos de nuestro propósito invariable de vencer el mal por el bien. Tenga además en cuenta tu prudencia que solo los eclesiásticos tienen la misión de presentarte las causas eclesiásticas. Por lo tanto, si piensas que debes dar muerte a los que incurren en tales delitos, nos amedrentarás para que no lleguen tales causas a tu tribunal por iniciativa nuestra. Y si eso se sabe, los donatistas se entregarán a una más licenciosa audacia, para nuestra ruina, mientras a nosotros se nos impone la necesidad de dejarnos matar por ellos espontáneamente antes de llevarlos a tu tribunal para que los mates. Por favor, no recibas con desdén esta amonestación, demanda y súplica mía. Supongo que recordarás que podría tener una gran confianza en ti, aunque yo no fuera obispo y tú estuvieses encumbrado en una mucho más alta dignidad. Conozcan cuanto antes los herejes donatistas, por un edicto de tu excelencia, que siguen en vigor las leyes promulgadas contra su error, pues creen que ya no son válidas y se jactan de ello. Por lo menos de ese modo podrán dejarnos en paz un tanto. Mucho nos ayudarás para que nuestros trabajos y peligros rindan su fruto si consideras esto. No es cuestión de reprimir con leyes imperiales a esa secta baladí, llena de insano orgullo; los criminales aparecerán ante su conciencia y ante sus partidarios como mártires de la verdad y de la justicia. Lo que importa es que los criminales aparezcan convictos e informados con documentación fehaciente de sus delitos en las actas de tu prestancia o de tus jueces subordinados, para que los detenidos por tus órdenes dobleguen, si es posible, su endurecida voluntad y lean a otros el proceso para su salud. La mera represión, sin la instrucción, es una diligencia pesada más bien que útil, aunque se ejecute para evitar tan grande mal y lograr tan grande bien. ${ }^{29}$

29 San Agustín, Epístola 100,2 (PL 33,366-367). trad. de Lope Cilleruelo, OSA, en $<$ https://www.augustinus.it/spagnolo/lettere/lettera_101_testo.htm> [consulta: 13 septiembre 2021]. 
Estas palabras plasmadas por la pluma del prelado africano dirigidas al procónsul Donato resumen a la perfección su postura. Hay que recordar la existencia de las leyes para que tengan carácter disuasivo, pero cuando toque aplicarlas hay que hacerlo con moderación y dentro de los límites de la cosmovisión cristiana del hombre que, aunque libre para pecar y delinquir, sigue siendo, por su naturaleza de creatura, imagen de Dios. "Dejarse matar antes que denunciar". Esta es la consigna y"amenaza" que el de Tagaste le plantea a su interlocutor epistolar. ${ }^{30} \mathrm{Si}$ las denuncias presentadas por los eclesiásticos ante los tribunales civiles por los delitos y crímenes cometidos por los donatistas terminan en la aplicación de la pena de muerte para estos, entonces la conducta cristiana consistirá en dejarse matar antes que denunciar. Difícil lo tienen aquellos que sostienen que san Agustín cambió el rumbo doctrinal de la Iglesia con respecto a la pena capital. “De hecho negó expresamente la eticidad de la pena capital e indirectamente la negó también de derecho" ${ }^{31}$

Después de san Agustín, la posición de la Iglesia oficial siguió siendo la misma, a saber, de rechazo frontal a la pena de muerte. Esto lo vemos en las disposiciones establecidas por los concilios toledanos del siglo vII. Era algo habitual que los príncipes requirieran los servicios de los sacerdotes para administrar justicia debiendo aplicar para ello las leyes, entre las que se incluía la pena máxima. Ante esta política de hechos consumados, el Iv Concilio de Toledo del año 633 recogía en su canon XXXI la incompatibilidad entre el sacerdocio y el oficio de juez, puesto que el sacerdote tiene la encomienda de salvar almas mientras que el magistrado, por razón de su cargo, debe, a veces, aplicar sentencias condenatorias. El único caso en el que se le permite a un presbítero asumir la función judicial es cuando previamente y bajo juramento, consiga la promesa de los mismos príncipes que lo promueven en la magistratura, de que podrán aplicar la indulgencia evitando así la imputación de la pena capital. En el supuesto de que tal promesa no consiguiera obtenerla de los príncipes tendría que rechazar el ofrecimiento y si no lo hiciera, tal sacerdote

\footnotetext{
30 Algo parecido propone el apóstol Pablo cuando en su primera carta a la comunidad creyente de Corinto les plantea que se dejen despojar antes que acudir a los tribunales civiles para que sean los jueces paganos los que emitan los correspondientes fallos. Cf. 1 Cor 6,1-7.

31 BlázQuez, Pena de muerte, 28.
} 
será expulsado de su cargo por haberse manchado las manos con sangre humana. ${ }^{32}$ Esta misma disciplina se mantendrá y se recordará en otros concilios toledanos como hace el canon vi del Concilio XI del año 675 en el que se subraya la ilicitud de los juicios de sangre llevados a cabo por los eclesiásticos, y si alguno de ellos, obviando estas disposiciones, hubiese sentenciado a muerte a algún reo, será destituido de su honor y de su cargo, y no siendo esto suficiente, será además encarcelado a perpetuidad. Aunque no se le negará la comunión antes de morir, pues se debe buscar siempre, a tenor de las enseñanzas evangélicas, la conversión del pecador. ${ }^{33}$ Pocos años después, los obispos de la Hispania visigoda se volvieron a reunir en el Concilio XII en la capital toledana y entre las disposiciones que establecieron se encontraba la prohibición de dar muerte a alguien por incurrir en idolatría. Ciertamente se trata de un pecado gravísimo. Sin embargo, el canon xI del citado concilio establece la destrucción de aquellos objetos considerados sacrílegos al ser utilizados para concurrir en la idolatría y un castigo para quienes hayan idolatrado, pero queda excluida la pena de muerte por este delito. Las penas máximas que se le podrán aplicar a los idólatras serán la excomunión y el destierro. ${ }^{34}$

32 "Saepe príncipes contra quoslibet majestatis obnoxios sacerdotibus negotia sua committunt; sed quia sacerdotes a Christo ad ministerium salutis electi sunt, ibi consentiant regibus fieri iudices, ubi jureiurando supplicii indulgentia promitittur, non ubi discriminis sententia praeparatur. Si quis ergo sacerdotum contra hoc commune consultum discussor in alienis periculis extiterit, sit reus effusi sanguinis apud Christum, et apud ecclesiam perdat proprium gradum": Francisco Antonio González - Juan Tejada y Ramiro (eds.), Colecciones de Cánones y Concilios de la Iglesia de España y de América, Vol. 2, Madrid, Imp. J.M. Alonso, $1861,286-287$.

33 "His a quibus Domini sacramenta tractanda sunt judicium sanguinis agitare non licet. Ideo magnopere talium excessibus prohibendum est, ne indiscretae praesumptionis motibus agitati aut quod morte plectendum est sententia propria judicare praesumant, aut truncationes quaslibet membrorum in quibuslibet personis tale aliquid fecerit, et concessi ordinis honore privatus et loco sub perpetuo damnationis teneatur religatus ergastulo, cui tamen communio exeunti ex hac vita non neganda est propter Domini misericordiam, qui non vult peccatoris mortem sed ut convertatur et vivat": GonzÁLEZ - Tejada y RAMiro, Colecciones de Cánones y Concilios, 444.

34 "[... Praecepta haec Domini non in ultione sed in terrore delinquentium apponentes non mortis per hanc sententiam promulgamus, sed cultores idolorum, veneratores lapidum, accensores faculorum et excolentes sacra fontium vel arborum admonemus, ut agnoscant quod ipsi se spontaneae morti subjiciunt 
Como se puede ver, el respeto a la vida humana ha sido uno de los pilares fundamentales de los concilios toledanos pues la fidelidad a la enseñanza del Evangelio no permitía argumentar a favor de la pena de muerte.

Una centuria más tarde, ya en el siglo viII, Zacarías, el último papa bizantino, le escribirá una carta a los francos y a los galos en la que repetirá cuál era la enseñanza y la praxis eclesial en materia penal. En esta misiva, el pontífice insistía en que es incongruente la fe en Jesucristo con ciertas conductas contrarias a la vida humana. Hacía mención especial a los sacerdotes que entregaban a la justicia a determinados hombres para que fueran ejecutados por sus delitos. Aunque la ley prescriba tales sanciones, no le es lícito a un presbítero entregar a nadie a los tribunales por graves que fueran sus crímenes, pues actuando así, no podrían ser buenos ministros del evangelio de la vida aquellos que han manchado sus manos con sangre. ${ }^{35}$ Un siglo más tarde se volverá a insistir en esta cuestión sobre todo cuando la Sede Apostólica le recordó al rey Carlos de los francos que la Iglesia imponía a los cristianos el deber moral de abstenerse de portar armas y de luchar contra los enemigos. Y con respecto a los ministros se volvía a subrayar la doctrina ya expuesta por el papa Zacarías, a saber, que si un sacerdote se veía envuelto directa o indirectamente en algún caso legal que implicara la aplicación de la pena de muerte a un ser humano, que fuera inmediatamente depuesto de su ministerio. Estas medidas adoptadas por la Sede Apostólica fueron aceptadas

qui diabolo sacrificare videntur.[...] Ac proinde omne sacrilegium idolatriae vel quidquid illud est contra sanctam fidem in quo insipientes homines captivati diabolicis culturis inserviant, sacerdotis vel judicis instantia, inventa haec sacrilegia eradanturet exterminia truncentur [...] Quod si ingenuorum personae his erroribus fuerint implicatae et perpetua excommunicationis sententia ferientur et arctiori exilio ulciscentur": GonZÁLeZ - TejadA y RAmiro, Colecciones de Cánones y Concilios, 479-480.

35 "[...] Habuistis enim peccatis facientibus nuncusque falsos et erroneos sacerdotes, unde et cunctae paganae gentes vobis pugnantibus praevalevant, quia non erat differentia inter laicos et sacerdotes, quibus pugnare licitum non est. Qualis enim victoria dari potest, ubi sacerdotes una hora dominica pertractant mysteria, et Christianis corpus dominicum porrigunt pro suarum animarum redemptione, et postea Christianos, quibus hoc ministrare debuerant, aut paganos, quibus Christum praedicare, propriis sacrilegisque manibus necant? [...]": Joannes Dominicus MAnsi, Sacrorum Conciliorum Nova et Amplissima Collectio, Vol. 12, Graz (Austria), Akademische Druck - U.Verlagsanstalt, 1960, 380. 
por el citado rey franco tal y como se recoge en las Capitulares del diácono Benedicto. ${ }^{36}$

Otro papa, esta vez ya en el siglo IX, será el encargado de volver a recordar la posición de la Iglesia sobre la pena de muerte. Se trata del pontífice Nicolás I. El contexto de su pronunciamiento hay que ubicarlo en los acontecimientos acaecidos en Bulgaria. El rey Kan Boris había impuesto el cristianismo como religión oficial entre los búlgaros. Esta decisión vino acompañada por una serie de protestas por parte de las comunidades paganas que se opusieron a la decisión adoptada. Muchas de estas protestas fueron frenadas y contestadas por Kan Boris por medio de la violencia. Una vez controladas las insurrecciones el dirigente búlgaro le escribe una carta al obispo de Roma para que le ayude a organizar la Iglesia en su país. El pontífice le contesta a su misiva, pero lo hace en un tono de enfado al conocer los métodos empleados para sofocar el levantamiento de una parte de la población. La intención de la carta redactada por Nicolás I era doble. Por un lado, mitigar los impulsos violentos del rey en futuras acciones $y$, en segundo lugar, recriminarle su mala praxis como gobernante cristiano porque llevó a la muerte a muchas de las personas que se habían opuesto a su decisión de hacer del cristianismo la religión oficial del país. Un gobernante cristiano, recordará el papa, debe actuar siempre con misericordia con aquellos a los que ha vencido y en modo alguno se puede aplicar la pena de muerte para los disidentes. ${ }^{37}$ No solo le recriminó el haber llevado a la muerte a cientos de personas, sino que también desaprobó otros métodos empleados como la tortura por ser contraria a la ley divina. Podríamos citar más ejemplos, pero consideramos que con los ya expuestos podemos sacar la conclusión de que durante el primer milenio la Iglesia se mostró abiertamente contraria a la aplicación de la pena de muerte por

36 " [...] Karolus, gratia Dei rex regnique Francorum rector et devotus sactae ecclesiae defendor atque adiuntor in omnibus. Apostolicae Sedis hortatu omniumque fidelium nostrorum et maxime episcoporum ac reliquorum sacerdotum consultu, servis Dei per omnia omnibus armaturam portare vel pugnare aut in exercitum et in hostem pergere omnino prohibemus, nisi illi tantummodo qui propter divinum ministerium missarum scilicet sollemnia adimplenda et sanctorum patrocinia portanda ad hoc electi sunt": Benedicti Diaconi, Capitularium Collectio, 123 (PL 97,812).

37 Cf. Epístola 97 (PL 119,989). 
ser una medida opuesta al espíritu evangélico. ¿Ocurrió lo mismo en el segundo milenio?

\section{CONSIDERACIÓN DE LA PENA DE MUERTE EN EL SEGUNDO MILENIO}

Este período se encuentra marcado por el pensamiento de santo Tomás de Aquino quien se encargaría de justificar racionalmente la licitud moral de la pena de muerte por parte de las autoridades competentes. No se trata de una conclusión novedosa pues ya dijimos que, durante el primer milenio, aun fijándose una posición generalizada de rechazo a la última pena, no dejó nunca de existir voces discordantes dispuestas a justificarla. Además, en los albores del segundo milenio encontramos la reflexión de algunos autores que allanaron el camino a la teorización tomista de la pena capital como Ivo de Chartres, Graciano o Pedro de Poitiers. El primero, apellidado así por haber sido obispo de esa ciudad, comenzará a romper el hielo en defensa de la pena capital. Para ello se apoyará en algunos textos de la Escritura y en la autoridad de algunos pensadores del pasado, especialmente en San Jerónimo. De él tomará un texto, basado en los comentarios al profeta Ezequiel en el que el de Estridón afirmaba que el que golpea a los malos y da muerte a los que son peores actúa como ministro de Dios. ${ }^{38}$ Ivo de Chartres seguirá con su recurso a San Jerónimo para seguir justificando la postura de la licitud de la pena de muerte. Para ello recurrirá a otro texto del egregio biblista, esta vez del comentario al libro de Jeremías en el que sostiene que quien mata a los malhechores no comete un acto de asesinato sino un acto de justicia en cuanto que salvaguarda el bien común. Dar muerte a los homicidas es propio del ministerio de la ley. ${ }^{39}$ La manera que tiene Ivo de citar a San Jerónimo nos resulta un tanto tendenciosa pues no ha tenido en cuenta el contexto de las palabras del autor de laVulgata. En cualquier caso, a Ivo se le puede atribuir el hecho de que empezara a poner las bases teóricas de la justificación de la última pena, sobre todo porque en su argumentación postula la separación entre el poder civil y el eclesiástico atribuyéndole al primero la potestad de

38 "Qui percutit malos in eo quod mali sunt, et habet causam interfectionis ut percutiat pessimos, minister Dei est": SAN JeRÓNIMO, In Ezechielem, 3.9.

39 "Homicidas enim et sacrilegos et venenarios punire, non est effusio sanguinis, sed legum ministerium": SAN JeRónImo, In Jeremiam, 4.22. 
aplicar la pena de muerte a los malhechores mientras que el segundo debía abstenerse de todo juicio condenatorio que implicara la efussio sanguinis.

Por su parte, Graciano, en su Decretum Gratiani o Concordia discordantium canonum también planteará justificaciones a la aplicación de la pena capital, justificaciones que hará depender de la paz de la Iglesia. Es decir, si para mantener el orden social y la unidad de la fe fuese necesario recurrir a las leyes que estipulan la muerte de aquellos que alteran este orden no podría decirse que esto fuera algo ilícito puesto que la necesidad exige tales medidas. ${ }^{40}$

Por otro lado, tenemos el planteamiento de Pedro de Poitiers quien ya en el siglo XII comenzará a justificar que el quinto mandamiento del decálogo no prohíbe la aplicación de la pena de muerte a los malhechores. La ilicitud del mandamiento estriba en el sentimiento con que se ejecute. ${ }^{41}$ De este modo, argumenta que proceder a dar muerte a alguien por odio o rencor estaría mal, pero hacerlo en virtud de la justicia social y de la paz de la Iglesia estaría bien. Este planteamiento será recurrente por el contexto histórico en el que se desarrolla que es cuando las herejías cátaras y valdenses irrumpen desestabilizando la convivencia entre cristianos.

Esta nueva situación histórica llevará a la Teología a reflexionar acerca de la moralidad de la aplicación de la pena de muerte que, como se ha indicado más arriba, no es más que dilucidar qué es lo que se encuentra prohibido en el quinto mandamiento del decálogo. Tal precepto fue interpretado en sentido absoluto en los primeros siglos del cristianismo como ya hemos comentado, por lo que no se permitía aplicar la pena de muerte en ninguna circunstancia. Pero a comienzos del segundo milenio, conforme la noción de cristiandad europea se iba consolidando, se empezó a cuestionar el carácter absoluto de esta prohibición, aunque seguía habiendo defensores de la interpretación originaria. El quinto mandamiento, ¿implica una prohibición absoluta o no? Para responder a esta pregunta no podemos perder de vista que nos encontramos ante una norma cuya finalidad no es otra que salvaguardar un valor. En el caso que nos ocupa el "no matarás" en cuanto norma tiene como cometido proteger el valor de la vida humana. Ahora bien, los moralistas, al estudiar

40 Cf. Graciano, Decretum Gratiani, C. XXXIII, q.V, c.47, 1269.

41 Cf. Pedro de Poitiers, Sent. 4.4 (PL 211,1150). 
la obligatoriedad del cumplimiento de la normatividad la clasifican en dos grandes bloques. Por un lado, estarían las normas universales que serían aquellas que habría que respetar siempre y en todo lugar en cuanto que no admiten excepciones. Y, por otro lado, estarían las normas generales que serían aquellas que habría que respetar pero que en circunstancias muy concretas y especiales podrían admitir excepciones. Hecha esta distinción reformulamos la pregunta anterior: el quinto mandamiento del decálogo, ¿es una norma universal o general? Durante el primer milenio la posición de la Iglesia se inclinó hacia la primera de las opciones, pero en los dos primeros siglos del segundo milenio la balanza se fue igualando hasta llegar a la escolástica en donde se produjo un enfrentamiento académico entre dos escuelas teológicas con posicionamientos contrarios a la temática planteada. Una de estas escuelas era la franciscana, llamada también escotista, que defendía el carácter absoluto de la prohibición del quinto mandamiento y, por tanto, su consideración como norma universal. La otra, era la escuela dominica, llamada también tomista, que tendía a interpretar el precepto del "no matarás" como una norma general, es decir, como una ley que hay que respetar y cumplir pero que en virtud de ciertas circunstancias se aceptaba la posibilidad de aplicar excepciones a casos concretos. De esta pugna intelectual salió victoriosa la segunda de las escuelas por lo que, a partir del siglo xIII, la Iglesia basculó su posicionamiento oficial con respecto a la aplicación de la pena de muerte. Esta se vio como algo no deseable pero que estaría permitida en ciertos casos si el contexto social así lo justificaba. Para el Aquinate, aplicar la última pena a un inocente es algo siempre ilícito, pero aplicarla a un delincuente, a un malhechor $\mathrm{o}$ a alguien que ponga en peligro la paz social es algo debido y lícito siempre que tal castigo sea aplicado por la autoridad competente y no por un particular.

En su argumentación acerca de la licitud de la pena de muerte utiliza el símil de la amputación exponiéndolo de este modo:

Según se ha expuesto (a.1), es lícito matar a los animales brutos en cuanto se ordenan de modo natural al uso de los hombres, como lo imperfecto se ordena a lo perfecto. Pues toda parte se ordena al todo como lo imperfecto a lo perfecto, y por ello cada parte existe naturalmente para el todo. Y por eso vemos que, si fuera necesaria para la salud de todo el cuerpo humano la amputación de algún miembro, por ejemplo, si está podrido y puede inficionar a los demás, tal amputación sería laudable y saludable. Pues bien: 
cada persona singular se compara a toda la comunidad como la parte al todo; y, por tanto, si un hombre es peligroso a la sociedad y la corrompe por algún pecado, laudable y saludablemente se le quita la vida para la conservación del bien común; pues, como afirma san Pablo un poco de levadura corrompe a toda la masa. ${ }^{42}$

Para el Aquinate, la justificación de la pena de muerte tiene un basamento social ya que sería el bien común lo que demandaría su aplicación para exterminar a aquellos que comprometan el orden y la convivencia de la comunidad. En la baja Edad Media, la religión cristiana era el elemento que garantizaba la unidad territorial y la noción de pertenencia a una colectividad. Esta unidad se vio amenazada con la introducción de ciertas herejías como la cátara o la valdense que ya hemos nombrado. Por lo tanto, para la mentalidad de la época, eran los herejes los causantes de los desórdenes sociales. En este sentido, la herejía se concebía no sólo como un pecado contra la fe sino sobre todo como un gravísimo delito al perturbar la paz y la armonía de la sociedad. Si las enseñanzas contra la sana doctrina hubiesen sido solamente pecados contrarios a la fe, la Iglesia habría procedido con la excomunión y ya está. Pero al considerarse la herejía como un delito de orden social había que proceder penalmente contra los infractores aplicando la pena más severa si los delincuentes eran pertinaces en sus posturas. Sobre esto el Doctor Angélico se pronuncia en los siguientes términos:

En los herejes hay que considerar dos aspectos: uno, por parte de ellos; otro, por parte de la Iglesia. Por parte de ellos hay en realidad pecado por el que merecieron no solamente la separación de la Iglesia por la excomunión, sino también la exclusión del mundo con la muerte. En realidad, es mucho más grave corromper la fe, vida del alma, que falsificar moneda con que se sustenta la vida temporal. Por eso, si quienes falsifican moneda, $\mathrm{u}$ otro tipo de malhechores, justamente son entregados, sin más, a la muerte por los príncipes seculares, con mayor razón los herejes convictos de herejía podrían no solamente ser excomulgados, sino también entregados con toda justicia a la pena de muerte. Mas por parte de la Iglesia está la misericordia a favor de la conversión de los que yerran, y por eso no se les condena, sin más, sino después de una primera y segunda amonestación (Tit 3,10), como enseña el Apóstol. Pero después de esto, si sigue todavía

42 Santo Tomás de Aquino, Summa Theologica, II-II, q. 64, art. 2, Tomo III, Madrid, BAC, 2005, 530-531. La cita paulina es 1 Cor 5,6. 
pertinaz, la Iglesia, sin esperanza ya de su conversión, mira por la salvación de los demás, y los separa de sí por sentencia de excomunión. Y aún va más allá relajándolos al juicio secular para su exterminio del mundo con la muerte. A este propósito afirma san Jerónimo y se lee en el Decreto: Hay que remontar las carnes podridas, y a la oveja sarnosa hay que separarla del aprisco; no sea que toda la casa arda, la masa se corrompa, la carne se pudra y el ganado se pierda. Arrio, en Alejandría, fue una chispa, pero, por no ser sofocada al instante, todo el orbe se vio arrasado con su llama. ${ }^{43}$

Estas palabras dejan clara la posición del Aquinate con respecto a la pena máxima. En los casos en los que no haya esperanza de que se produzca la enmienda, la Iglesia debe actuar entregando al hereje al brazo secular para que sea este quien aplique el castigo. Si comparamos este planteamiento con el de san Agustín vemos una enorme diferencia. También el de Tagaste se encontraba ante una situación de turbulencia social causada, entre otros avatares históricos, por la herejía donatista y su célula más beligerante, los circunceliones. Sin embargo, no pasaba por su mente el entregarlos a los tribunales regidos por el procónsul Donato para que fueran ejecutados y esto aun teniendo en cuenta que los circunceliones no solo incurrían en herejía sino también en latrocinios, violaciones y asesinatos, pues no en vano se les reconocía como el cuerpo terrorista del donatismo.

Con santo Tomás, ya se ha consumado el cambio de mentalidad que dos siglos antes se había tímidamente incoado con Ivo de Chartres quien fue el primero en teorizar acerca de la separación entre el poder civil y el eclesiástico en materia penal. Cuestión del todo medular ya que en ella encontramos las diferencias entre las potestades seculares y los ministros de la Iglesia de tal modo que tendrían que ser los primeros los encargados de aplicar la pena de muerte mientras que los segundos tendrían que abstenerse de ello. ${ }^{44}$

Tras la muerte del Aquinate, el tomismo se consagró como marco académico hasta el punto de que muchas de sus afirmaciones y sentencias vertidas en sus obras se consideraron como verdades reveladas. Todo esto se acentuó cuando la Summa Theologica se estableció como manual de estudio para profesores y alumnos. De este modo el pensamiento tomista se convirtió en la teología oficial de la Iglesia por lo que apenas se dio el disenso. Es cierto que no todas

\footnotetext{
43 Ibidem, II-II, q. 11, art. 3,127-128.

44 Cf. Blázquez, Pena de muerte, 45-46.
} 
las enseñanzas recogidas por santo Tomás en sus escritos gozan del mismo valor, pero el discernimiento intelectual que permitiera diseccionarlas no estaba al alcance de todos ni todos aquellos que sí estaban capacitados para hacerlo se atrevían a ello. ${ }^{45}$ Esto condujo a una paulatina consolidación de las tesis tomistas, incluida la justificación de la pena de muerte para aquellos que perturben el orden social. La postura jurídica del Aquinate con respecto a la pena capital se fue diseminando por la mayoría de los centros de estudios y universidades con el paso del tiempo. En el siglo XVI, la universidad de Teología más importante era la de Salamanca y su docente más ilustre Francisco de Vitoria. El salmantino hizo suyas las tesis tomistas y actuó como un verdadero apologista del pensamiento del Angélico. En este sentido, el padre del Derecho Internacional no escatimó esfuerzo alguno para combatir a los escotistas que eran los únicos que se atrevían a cuestionar los fundamentos teológicos presentes en la Summa Theologica y que sostenían que la prohibición inscrita en el quinto precepto del decálogo tenía carácter absoluto. De Vitoria sacará todo su arsenal discursivo para contrarrestar el planteamiento de la escuela franciscana defendiendo la licitud moral de aplicar la pena máxima en los casos en los que las circunstancias lo requieran en virtud del bien común. En realidad, no realiza ningún aporte novedoso con relación a esta cuestión, simplemente se limita a defender y a justificar cuantas afirmaciones encuentra en su admirado santo Tomás.

Durante las dos centurias siguientes, la aplicación de la pena capital como recurso del Estado para mantener el orden social se fue consolidando como teoría jurídica hasta el punto de que nadie se atrevió a cuestionarla. De hecho, fue en este período donde se asentaron las tres razones en las que se apoyaba la justificación de la pena capital: la salvaguarda del bien común; la pena como mecanismo disuasivo para cometer delitos execrables; y la ejecución como compensación por los crímenes perpetrados. Hubo que esperar hasta finales del siglo XVIII para encontrar una crítica abierta con respecto a esta cuestión. La crítica vino de la pluma del noble milanés Cesare Beccaria quien en su obra Dei delitti e delle pene cuestiona los argumentos favorables a la aplicación de la última pena. El italiano

45 La excepción a lo que acabamos de decir la constituyen los escotistas que eran contrarios a la pena de muerte. En realidad, la escuela franciscana ha sido la única que se ha opuesto firmemente a este planteamiento tomista. 
sostiene que la pena de muerte no es en modo alguno un derecho sino "solo una guerra de la nación contra un ciudadano". ${ }^{46}$ Para el transalpino la muerte no es útil ni necesaria para proteger el bien común el cual puede mantenerse con la sola privación de la libertad del delincuente aunque admite dos motivos por los cuales sí podría aplicarse. El primero, cuando el delincuente, ya privado de su libertad, pusiera en peligro el bien social de la nación a causa de posibles revueltas bélicas encaminadas a liberarlo para que siga encabezando el movimiento que lo ha puesto fuera del alcance de la ley.Y el segundo de los motivos sería que la muerte del delincuente fuese el único medio para refrenar otros crímenes. ${ }^{47}$ Fuera de estas circunstancias, la apelación a la última pena no tendría justificación alguna. El pensamiento del italiano alcanzó un cierto eco en el ámbito del derecho civil iniciándose así el movimiento abolicionista pero no tuvo la misma influencia en el campo militar ni tampoco en el eclesiástico, pues en estos dos últimos se seguía aceptando y justificando, al menos en el plano teórico, la licitud de la pena de muerte para los delitos de extrema gravedad. En el terreno puramente eclesial, que es el que nos interesa, hubo que esperar a la segunda mitad del siglo xx para encontrar un cierto viraje en los planteamientos de la moral católica. De hecho, el último papa en pronunciarse en su favor fue Pío XII, quien no descarta la eticidad de la aplicación de la pena de muerte por parte de la autoridad civil de acuerdo con las tesis tomistas argumentando que las personas que han cometido ciertos delitos se hacen indignas de seguir viviendo. En uno de sus muchos discursos a la comunidad médica afirmó que:

Aun en el caso de que se trate de la ejecución de un condenado a muerte, el Estado no dispone del derecho del individuo a la vida. Está reservado al Poder público privar al condenado del“bien” de la vida, en expiación de su falta, después de que, por su crimen, él se ha desposeído de su "derecho" a la vida. ${ }^{48}$

46 Cesare BeCCaria, Tratado de los delitos y de las penas, Madrid, Universidad Carlos III, 2015, 57.

47 Cf. Beccaria, Tratado de los delitos, 57.

48 Pío XII, Discurso al I Congreso Internacional de Hispatología del Sistema Nervioso 28 (13-septiembre-1952), en AAS 44 (1952) 787. 
Después de esta intervención y otras parecidas por parte del citado papa, ya nunca más un sucesor de Pedro volvería a justificar la aplicación de la pena capital sobre un ser humano.

\section{EL CAMBIO DE SENSIBILIDAD}

A partir de la segunda mitad del siglo xx se empieza a vislumbrar, a nivel eclesial, un cambio de mentalidad con respecto a la licitud de la aplicación de la pena de muerte. Los papas del concilio, Juan xxIII y Pablo vi, en ningún momento de sus respectivos pontificados apelan a ella. Ni siquiera en los documentos conciliares encontramos una referencia a la pena capital en la que aparezca como una práctica justificable en ciertas circunstancias. Más bien parecen negarla, aunque eso sí, solo indirectamente. Efectivamente, el $\mathrm{n}^{\circ} 27$ de la constitución Gaudium et spes recoge un elenco de acciones que degradan la dignidad de la persona en la medida en la que suponen un atentado al respeto de la vida humana. ${ }^{49}$ En dicho elenco no se inscribe la pena de muerte, pero el contexto del pasaje, sobre todo en su relación con el siguiente número basado en el respeto y en el amor a los adversarios, hace suponer que el espíritu del concilio era contrario a la aplicabilidad de la pena máxima. ${ }^{50}$

Los años inmediatamente posteriores al concilio fueron años de duro trabajo para poder plasmar en otros documentos las novedades teológicas impulsadas por los padres conciliares tales como el nuevo Código de Derecho Canónico (1983) o el Catecismo de la Iglesia Católica (1992). Este último texto causó decepción en no pocos sectores teológicos porque cuando todo parecía indicar que se recogería en él la abolición de la pena de muerte a tenor de la nueva sensibilidad que se había gestado en años precedentes, la redacción final de los números 2262 al 2267 seguía incluyendo la aceptación de la pena capital. Tres años después, Juan Pablo II, publicaría Evangelium Vitae, la que sería la undécima carta encíclica del papa polaco. Muchos creyeron que sería en este documento donde el pontífice recogería la singularidad del ethos cristiano rechazando la máxima pena, sobre todo porque con su gesto de perdonar a quien intentó matarlo había

\footnotetext{
49 Cf. ConcilioVaticano II, Constitución Pastoral de la Iglesia en el mundo Gaudium et Spes (7-diciembre-1965) no 27, en AAS 58 (1966) 1047-1048.

50 Cf. BlázQuez, Pena de muerte, 129-130.
} 
mostrado, no solo al pueblo católico sino a la humanidad entera, cuál debía ser la actitud del creyente con respecto a aquellos que cometían delitos graves. El papa Wojtyla nunca solicitó la pena de muerte para el turco Mehmet Ali Agca quien el 13 de mayo de 1981 intentó acabar con su vida. Más bien hizo todo lo contrario, y así, en diciembre de 1983, en una visita realizada a la prisión en la que se encontraba recluido, le regaló el perdón. El gesto quedó impreso en la mente de muchas personas con independencia del credo que profesaran. Por ello, al ser la encíclica citada un texto en el que el pontífice quiso centrarse en la dignidad de la persona y en condenar todas las acciones que atentan contra ella, muchos esperaron que hubiera una condena expresa de la pena de muerte por cuanto que suprimir la vida de un ser humano implicaría no valorar su dignidad como hijo de Dios y como miembro de la sociedad. Sin embargo, tal condena nunca apareció en la Evangelium vitae, aunque es justo reconocer que se mitigó el lenguaje usado y que aparecen algunas enmiendas si lo comparamos con el texto del Catecismo de 1992. ${ }^{51}$

Sea como fuere, lo cierto es que Juan Pablo II no se atrevió a modificar la enseñanza de la Iglesia con relación a la licitud de la aplicación de la pena de muerte en la citada encíclica, no sabemos si por la presión recibida de determinados grupos afines a la tradición tomista o bien por propia convicción. No obstante, la enseñanza había quedado lo suficientemente matizada como para permitir que en años sucesivos se pudiera llegar a una reformulación que no supusiera una revolución doctrinal que provocara heridas en los sectores más conservadores.

Este camino abierto por su predecesor lo continuó Benedicto XVI, quien otrora fuera el Prefecto de la Congregación para la Doctrina de la Fe y, por consiguiente, el encargado de presentar el texto del nuevo Catecismo postconciliar al orbe católico. El papa alemán tampoco se atrevió a llevar a cabo una modificación del Catecismo que recogiera el cambio de sensibilidad reinante en el seno eclesial con respecto a la pena de muerte. Sin embargo, siguió arando el terreno para que pudiera fructificar la nueva mentalidad de justicia social que llevaba a concebir las penas no como un castigo sino como un

51 Cf. Niceto BlázQuez, "La pena de muerte en el Catecismo de la Iglesia”, Studium 59/1 (2019) 24. Cf. JuAn Pablo II, Carta Encíclica Evangelium vitae (25-marzo-1995), nº 56, en AAS 87 (1995) 463-464. 
medio de conversión y reinserción. Entre sus gestos cabe recordar su afirmación en Africae munus en la que pedía la eliminación de la pena capital así como las palabras finales pronunciadas en inglés de la Audiencia General del 30 de noviembre de 2011, en la que, dirigiéndose a los miembros de la comunidad de san Egidio, los exhortaba a seguir trabajando por la abolición de la pena de muerte en el mundo. ${ }^{52}$

Si bien es cierto que tanto Juan Pablo II como Benedicto XVI no llevaron a cabo la extirpación de la argumentación teológica-penal propia de la neoescolástica inserta en el Magisterio de la Iglesia con relación a la temática que nos ocupa, que dicho sea de paso estaba basada más en la doctrina social aristotélica que en la enseñanza evangélica, no menos cierto es el hecho de que sus respectivos pontificados sirvieron de abono para que el primer papa argentino de la historia se atreviera a materializar el tan esperado cambio. Tal modificación llegó, pero no exenta de problemáticas. Antes de la redacción definitiva del $\mathrm{n}^{\circ} 2267$ del Catecismo, el papa Francisco encargó a una Comisión especializada que estudiara la cuestión desde el punto de vista histórico, doctrinal y jurídico. Los miembros encargados del estudio se dedicaron durante varios años a la tarea encomendada. Tuvieron que sortear muchos obstáculos pues determinados sectores eclesiales no veían con agrado la posibilidad de modificar una inveterada enseñanza que llevaba siglos de arraigo en el Magisterio. De hecho, hubo un acontecimiento que hizo peligrar los esfuerzos

52 "Esta actividad pastoral es un servicio real que la Iglesia ofrece a la sociedad y que el Estado debe favorecer en aras del bien común. Junto con los miembros del Sínodo, llamo la atención de los responsables de la sociedad sobre la necesidad de hacer todo lo posible para llegar a la eliminación de la pena capital, así como para la reforma del sistema penal, para que la dignidad humana del recluso sea respetada": BENEDICTO XVI, Exhortación apostólica postsinodal Africae munus (19-noviembre-2011), n 83, en AAS 104 (2012) 276."I greet the distinguished delegations from various countries taking part in the meeting promoted by the Community of Sant'Egidio on the theme: No Justice without Life. I express my hope that your deliberations will encourage the political and legislative initiatives being promoted in a growing number of countries to eliminate the death penalty and to continue the substantive progress made in conforming penal law both to the human dignity of prisoners and the effective maintenance of public order. Upon all the English-speaking pilgrims present, including those from the United States, I invoke God's blessings of joy and peace!": BenEdicto XVI, Audiencia General (30-noviembre-2011). 
de la citada Comisión y fue la aparición, en 2017, de una nueva edición del Catecismo en lengua italiana para conmemorar el veinticinco aniversario de su publicación. Muchos quedaron consternados al poder constatar que el texto no recogía las propuestas de reforma de la Comisión ni tan siquiera se recogía el posicionamiento del propio pontífice manifestado en varias cartas o discursos previos a la publicación conmemorativa. ${ }^{53} Y$ es que no se debe soslayar el hecho de que el papa Francisco iba siguiendo con detenimiento las investigaciones de los obispos encargados del estudio cuyos resultados estaba asumiendo antes de la declaración definitiva. No solo iba dejando muestra de ello en las epístolas y alocuciones anteriormente citadas, sino que incluso en su segunda exhortación apostólica postsinodal, Amoris Laetitia, ya deja establecida cuál es la posición de su Magisterio y, por tanto, de la Iglesia. En el n 83 de este documento, en el contexto de la significación de la institución familiar, pone la pena de muerte al mismo nivel de valoración moral que el aborto y la eutanasia.Y así podemos leer:

[...] Es tan grande el valor de una vida humana, y es tan inalienable el derecho a la vida del niño inocente que crece en el seno de su madre, que de ningún modo se puede plantear como un derecho sobre el propio cuerpo la posibilidad de tomar decisiones con respecto a esa vida, que es un fin en sí misma y que nunca puede ser objeto de dominio de otro ser humano. La familia protege la vida en todas sus etapas y también en su ocaso. Por eso,'a quienes trabajan en las estructuras sanitarias se les recuerda la obligación moral de la objeción de conciencia. Del mismo modo, la Iglesia no sólo siente la urgencia de afirmar el derecho a la muerte natural, evitando el ensañamiento terapéutico y la eutanasia', sino también 'rechaza con firmeza la pena de muerte'. ${ }^{54}$

53 Estos discursos o pronunciamientos son: Carta del Santo Padre Francisco a los participantes del XIX Congreso Internacional de la Asociación Internacional de Derecho Penal y del III Congreso de la Asociación Latinoamericana de Derecho Penal y Criminología (30 de mayo de 2014); Carta dirigida a Federico Mayor, Presidente de la Comisión Internacional contra la Pena de Muerte (20 de marzo de 2015); llamada a la abolición de la pena de muerte después del rezo del ángelus 21 de febrero de 2016 con ocasión del encuentro que daría comienzo al día siguiente en la ciudad de Roma para tratar el tema de la abolición de la pena capital; videomensaje enviado al Congreso mundial contra la pena de muerte celebrado en Oslo del 21 al 23 de junio de 2016.

54 FrANCISCO, Exhortación apostólica postsinodal Amoris laetitia (19-marzo-2016) n 83 en AAS 108 (2016) 344-345. Las cursivas son nuestras. En realidad, las 
El camino ya estaba recorrido, las bases doctrinales estaban asentadas y la nueva sensibilidad jurídica se encontraba arraigada en la praxis pastoral de la Iglesia. Solo faltaba la materialización del cambio.Y este llegó definitivamente el 11 de mayo de 2018, fecha en la que el sucesor de Pedro, en audiencia concedida al Prefecto de la Congregación para la Doctrina de la Fe, el cardenal Luis F. Ladaria, autorizó el cambio de la redacción del n²267 del Catecismo quedando el texto de la siguiente manera:

Durante mucho tiempo el recurso a la pena de muerte por parte de la autoridad legítima, después de un debido proceso, fue considerado una respuesta apropiada a la gravedad de algunos delitos y un medio admisible, aunque extremo, para la tutela del bien común. Hoy está cada vez más viva la conciencia de que la dignidad de la persona no se pierde ni siquiera después de haber cometido crímenes muy graves. Además, se ha extendido una nueva comprensión acerca del sentido de las sanciones penales por parte del Estado. En fin, se han implementado sistemas de detención más eficaces, que garantizan la necesaria defensa de los ciudadanos, pero que, al mismo tiempo, no le quitan al reo la posibilidad de redimirse definitivamente. Por tanto, la Iglesia enseña, a la luz del Evangelio, que ‘la pena de muerte es inadmisible, porque atenta contra la inviolabilidad y la dignidad de la persona', y se compromete con determinación a su abolición en todo el mundo. ${ }^{55}$

La modificación fue promulgada el día 1 de agosto del mismo año, festividad de san Alfonso María de Ligorio, patrón de los moralistas. Con esto quedaba zanjada esta cuestión definitivamente.

últimas palabras del número presentado fueron tomadas directamente de las actas que los obispos le presentaron al Papa una vez concluido el Sínodo de la Familia celebrado un año antes. Cf. Relación final del Sínodo de los obispos al Santo Padre Francisco La vocación y la misión de la familia en la Iglesia y en el mundo contemporáneo (24-octubre-2015), nº 64, en AAS 107 (2015) 1204. En dicho sínodo participaron 265 obispos. El número 64 que incluía el rechazo a la pena de muerte fue aprobado con 247 votos a favor, 11 en contra y 7 abstenciones.

55 Nueva redacción del n 2267 del Catecismo de la Iglesia Católica sobre la Pena de Muerte, Rescriptum "Ex Audientia SS.MI". Se puede consultar en https:// www.vatican.va/roman_curia/congregations/cfaith/documents/rc_con_cfaith_ doc_20180801_catechismo-penadimorte_sp.html [Consulta 22 de septiembre de 2021]. 


\section{CONSIDERACIONES FINALES}

La posición adoptada por el Magisterio durante el pontificado del papa Francisco es el resultado de un largo recorrido. Dicha toma de postura no ha sido bien acogida por todos los estamentos de la Iglesia ni por todos los grupos que viven dentro de ella. De hecho, una vez dada a conocer la noticia del cambio de valoración moral con relación a la última pena se alzaron algunas voces discordantes con la decisión adoptada al considerar que se había cometido un grave error al modificar una enseñanza que sería una verdad de fide credenda tal y como han sostenido algunos teólogos, y, por lo tanto, irreformable. ${ }^{56}$ Así pues, la pregunta estaba ya servida. ¿Puede un papa contradecir la doctrina de la Iglesia presente en el Depósito de la fe? Si la Iglesia es infalible en relación con aquello que doctrinalmente enseña, ¿cómo puede ahora decir lo contrario de lo que ha sostenido durante siglos? Los interrogantes presentados son del todo pertinentes, pero consideramos que contienen errores de precisión.

En primer lugar, la licitud moral referente a la aplicabilidad de la pena capital a los malhechores en aquellas circunstancias en las que su ejecución se considere necesaria nunca ha formado parte del Depositum Fidei. Que una enseñanza o una determinada postura haya sido mantenida en la Iglesia no implica que forme parte del conjunto de verdades reveladas por Dios. El Depósito de la fe quedó cerrado con la muerte del último de los apóstoles y ya vimos que ninguno de ellos avaló la pena capital. La defensa de la licitud de su aplicación ha formado parte más bien de lo que se conoce como Depositum Ecclesiae, que sería el conjunto de las cosas que el cristianismo ha ido heredando a lo largo de los siglos. La pena de muerte se trata, sin duda, de algo heredado del Antiguo Testamento, de la filosofía social aristotélica y del Derecho Penal Romano, pero en modo alguno constituye una enseñanza del Maestro de Galilea ni de sus primeros discípulos.

Y, en segundo lugar, un cambio de enseñanza como el que estamos comentando no implica en modo alguno una contradicción doctrinal que ponga en entredicho el carácter infalible de la Iglesia.

56 "Es una verdad de fe, definida en la profesión de fe contra los valdenses (D. 425) y por León x contra Lutero (D 773)": Teófilo URDANOZ, "Introducción a la cuestión 64", en Santo Tomás de Aquino, Suma Teológica, T. VIII, Madrid, BAC, 1956, 422. 
Dicha infalibilidad está garantizada por el Espíritu Santo en relación con las doctrinas contenidas en el Depositum Fidei, pero como ya hemos dicho, la licitud moral de la pena de muerte no forma parte de dicho depósito. Con respecto al contenido del Depositum Ecclesiae, la Iglesia puede y debe modificar cuantas cosas considere necesarias para poder amoldarlas a las que sí han sido reveladas. Y esto es algo que la Esposa de Cristo ha hecho a lo largo de la historia. Hubo una época en que la Iglesia admitía la esclavitud y la tortura, hoy se consideran inadmisibles; hubo otra época en que no aceptaba la libertad religiosa, hoy se asume como un gran avance. Y así se podría ir concatenando enseñanzas que han sido reajustadas para adherirse a la verdad que Dios ha querido que conociéramos por su Revelación. ${ }^{57}$ El Depósito de la Fe es inmutable en sí mismo pero mudable con respecto a nuestro conocimiento. Y el conocimiento humano está condicionado por coordenadas históricas y socioculturales que influyen inexorablemente en nuestra comprensión y captación. Cuando la Iglesia afirma hoy que la pena capital es inadmisible lo hace a la luz del Evangelio que enseña que toda vida humana es sagrada y su dignidad inviolable por más que una persona se haya degradado con su pecado. Históricamente esta verdad no ha sido siempre comprendida de ahí que haya habido momentos en los que se haya pensado que determinadas acciones delictivas corroen de tal manera la naturaleza humana que convierten a un sujeto en un ser indigno de seguir viviendo. Descubrir que esta comprensión de la dignidad humana no se ajusta al Depósito de la Fe y querer corregirla no implica contradecirse doctrinalmente puesto que el contenido revelado no ha variado, solo nuestro conocimiento. Pues bien, esto es precisamente lo que ha ocurrido con la pena de muerte. Históricamente la Iglesia ha heredado de filosofías ajenas al espíritu evangélico una noción de dignidad que se ha basado en las acciones personales de

57 Hay ciertas cuestiones morales que han experimentado un cambio de comprensión a lo largo de la historia. Aunque es cierto que la Teología Moral profundiza en la noción de ley natural para fundamentar la licitud ética de determinadas acciones, no menos cierto es el hecho de que esta no debe ser considerada como una realidad rígida. Los primeros principios de la ley natural son inmutables pero los segundos principios tienen que ser analizados y comprendidos desde la perspectiva de la historicidad. Sobre esta cuestión cf. José Manuel MarTínez GuISASOLA, "Recuperación de la noción de ley natural frente al relativismo moral de occidente", Isidorianum 54 (2018) 288: https://doi.org/10.46543/ISID.1827.1035. 
los individuos y no en la naturaleza creatural de cada uno de ellos como imago Dei. Esta intelección nocional fue aprehendida por la Teología Moral a partir de la escolástica e integrada por la jerarquía de la Iglesia durante más de siete siglos en el Depositum Ecclesiae, jamás en el Depositum Fidei. ${ }^{58}$ La Esposa de Cristo le debe fidelidad absoluta a este último, no al primero, por eso el Espíritu Santo no permite que la Iglesia quite, altere o modifique su contenido ni tampoco que añada algo que no haya sido revelado por Dios. Pero con respecto al primero, el Magisterio puede corregir y modificar cuanto sea necesario para ajustar su enseñanza al segundo.Y esto es lo que, felizmente, ha hecho el papa Francisco sirviéndose del camino arado por sus predecesores.

58 Cf. BlázQuez, "La pena de muerte en el Catecismo”, 62-63. 
